\title{
Ionizing Radiation Risks to \\ Satellite Power Systems \\ (SPS) Workers in Space
}

$R-2683$

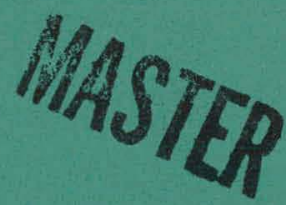

December 1980

Prepared for:

U.S. Department of Energy

Office of Energy Research

Solar Power Satellites Division

Under Contract No. W-7405-ENG-48

DOE/NASA

Satellite Power System

Concept Development

and

Evaluation Program 


\section{DISCLAIMER}

This report was prepared as an account of work sponsored by an agency of the United States Government. Neither the United States Government nor any agency Thereof, nor any of their employees, makes any warranty, express or implied, or assumes any legal liability or responsibility for the accuracy, completeness, or usefulness of any information, apparatus, product, or process disclosed, or represents that its use would not infringe privately owned rights. Reference herein to any specific commercial product, process, or service by trade name, trademark, manufacturer, or otherwise does not necessarily constitute or imply its endorsement, recommendation, or favoring by the United States Government or any agency thereof. The views and opinions of authors expressed herein do not necessarily state or reflect those of the United States Government or any agency thereof. 


\section{DISCLAIMER}

Portions of this document may be illegible in electronic image products. Images are produced from the best available original document. 


\section{NOTICE}

This report was prepared as an account of work sponsored by the United States Government. Neither the United States nor the United States Department of Energy, nor any of their employees, makes any warranty, express or implied, or assumes any legal liability or responsibility for the accuracy, completeness, or usefulness of any information, apparatus, product, or process disclosed, or represents that its use would not infringe privately owned rights. Reference herein to any specific commercial product, process, or service by trade name, mark, manufacturer, or otherwise, does not necessarily constitute or imply its endorsement, recommendation, or favoring by the United States Government or any agency thereof. The views and opinions of authors expressed herein do not necessarily state or reflect those of the United States Government or any agency thereof.

Ava1lable from:

National Technical Information Service (NTIS)

U.S. Department of Comerce

5285 Port Royal Road

Springfield, Virginia 22161

Price:

Printed Copy

$\$ 8.00$

Microfiche: $\quad \$ 4.00$ 


\section{lonizing Radiation Risks to Satellite Power Systems (SPS) Workers in Space}

December 1980

Prepared for:

U.S. Department of Energy

Office of Energy Research

Solar Power Satellites Division

Washington, D.C. 20585

$\downarrow$

Prepared by:

Lawrence Berkeley Laboratory

Berkeley, CA. 94720

Under Contract No. W-7405-ENG-48

DOE/NASA

Satellite Power System

Concept Development

and

Evaluation Program

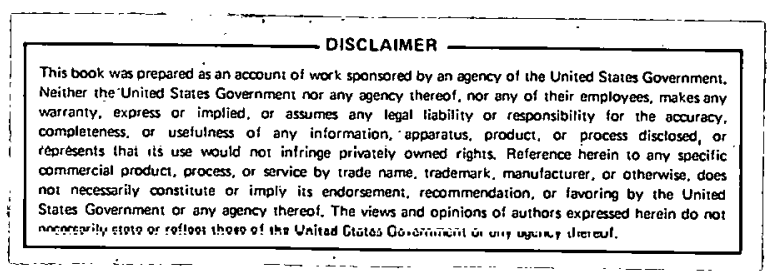




\section{THIS PAGE}

\section{WAS INTENTIONALLY LEFT BLANK}


FOREWORD

The work reported here was performed as a part of the Satellite Power System Concept Development and Evaluation Program Environmental Assessment. A committee was formed to support Margaret White of Lawrence Berkeley Laboratory, Task 2 manager, in assessing ionizing radiation risks to Satellite Power Systems workers in space. 1 The committee included the following, members:

\author{
Dr. John T. Lyman, Chairman \\ Lawrence Berkeley Laboratory \\ University of California \\ Berkeley, California
}

Dr. E. John Ainsworth

Lawrence Berkeley Laboratory

University of California

Berkeley, California

Dr. E. L. Alpen

Division Head

Biology and Medicine Division

Lawrence Berkeley Laboratory

University of California

Berkeley, California
Dr. Kenneth L. Jackson

Radiation Biology Department

University of Washington

Seattle, Washington

Dr. Stuart Nachtwey

Biomedical Applications Branch

Johnson Space Center

Houston, Texas
Dr. Charles Sondhaus

Department of Radiological Sciences

University of California Irvine

Medical Center

Orange, California

Dr. C. A. Tobias

Lawrence Berkeley Laboratory

University of California

Berkeley, California

Dr. Jacob I. Fabrikant

Lawrence Berkeley Laboratory

University of California

Berkeley, California 
THIS PAGE

\section{WAS INTENTIONALLY LEFT BLANK}


FOREWORD

SUMMARY.

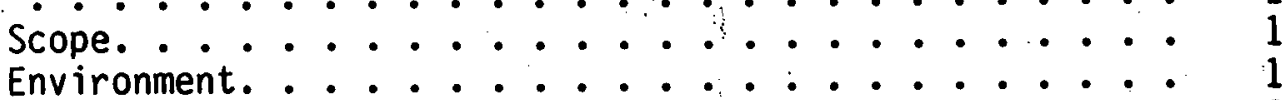

Radiation Dose................. 2

Health Risk Assessments. ............. 2

Conclusions................... 3

Recommendations................ 4

1. INTRODUCTION. . . . . . . ......... 5

Background ...................... 5

The Space Environment. .............. 5

2. REFERENCE SYSTEM EVALUATION . . • . . . . . . . . . 7

Estimated Absorbed Doses and Dose Equiva'lents in

SPS Workers ............... $\quad 8$

Low Earth Orbit. . . . . . . . . . . . 8

Transfer Ellipse ............... 8

Geosynchronous Orbit ............. 8

Total 90-Day Dose Equivalent ........... 11

Assessment of Risk for Cancer Induction. . . . . . 11

3. CONCLUSIONS AND RECOMMENDATIONS . . . . . . . . . 14

Health Risk Assessments ............ 14

Conclusions .................... 14

Recommendations.................. 15

APPENDIX A; SPACE RADIATION ENVIRONMENT. . . . . . . . . . 17

Trapped Electrons . ............... 17

Bremsstrahlung. . ................ 19

Trapped Protons ................ . . 19

Galactic Cosmic Rays............... 20

Solar Particle Events ............... . . 24

Different Effects of High- and LoW-LET Radiations . . . 24

Quality Factor................ 24

APPENDIX B, RADIATION HEALTH EFFECTS IN THE SPACE ENVIRONMENT 28

Early Effects................... . 28

Late Effects. .................. 29

Cancer..................... 31

Uncertainties in Dose-Response Relationships for

Radiation-Induced Cancer........... 32

Estimation of Space Radiation Induced Carcinogenic

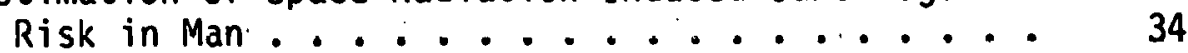

Genetically Related Ill-Health. .......... 38

Developmental Abnormalities in the Newborn ..... 38 
Effects on the Eye. . . . . . . . . . . . 39

Cataracts................. . . 39

Fertility ...................... 40

Female .................... 40

Male ..................... . . . 4 40

Other Health Effects of Radiation ............. . . 41

HZE Particle Radiation Effects ............ 41

APPENDIX C, GLOSSARY. . . . . . . . ....... 43

REFERENCES. ...................... 48 
SUMMARY

SCOPE

A reference Satellite Power System (SPS) has been designed by NASA and its contractors for the purposes of evaluating the concept and carrying out assessments of the various consequences of development, including those on the health of the space workers. The Department of Energy has responsibility for directing various assessments. Present planning calls for the SPS workers to move from Earth to a low earth orbit (LEO) at an altitude of 500 kilometers; to travel by a transfer. ellipse (TE) trajectory to a geosynchronous orbit (GEO) at an altitude of 36,000 kilometers; and to remain in GEO orbit for about 90 percent of the total time aloft.

This report deals with the radiation risks to the health of workers who will construct and maintain solar power satellites in the space environment. The charge to the committee was:

a. To evaluate the radiation environment estimated for the Reference System which could represent a hazard;

b. To assess the possible somatic and genetic radiation hazards;

c. To estimate the risks to the health of SPS workers due to space radiation exposure, and to make recommendations based on these conclusions.

\section{ENVIRONMENT}

GEO has the highest ionizing radiation intensity. The Reference System proposes that most workers will spend most of their tour in space in this environment. The radiation environment in GEO is known only with sufficient accuracy to predict the radiation dose in free space to within a factor of two, and then only for objects in orbit for relatively extended periods for which average values of the radiation environment may be used. The short-term enhancement of the radiation belt intensity caused by geomagnetic substorms may result in significant deviations from the average doses and could increase the risk to health of exposed individuals caught outside shielded. or protected areas. Solar particle events, which are rare events occurring most frequently in about eleven-year cycles, could increase the dose by a considerable factor.

Shielding is the major factor which influences the dose and thus the potential health risk to the SPS worker. With the exception of the storm cellar, the shielding of the Reference System used in these estimates of dose is the minimum amount of material needed for the 
structural integrity of the system. The galactic cosmic ray dose is not readily attenuated by shielding material. This may be a factor for setting a lower limit on the radiation dose if the bremsstrahlung dose is adequately attenuated.

\section{RADIATION DOSE}

Based on the Reference System model and subject to its limitations and assumptions, it is estimated that an SPS worker in GEO may be exposed to a dose of as much as 40 rem during any one 90-day mission. This estimate is based on the following assumptions:

a. That between 87 and 98 percent of the worker-years occur in GEO. For risk estimation, we therefore have assumed that the total mission will occur in GEO.

b. That cffective shieldilly of the worker will be equivalent to 8 grams per $\mathrm{cm}^{2}$ aluminum (which includes $5 \mathrm{~g} \mathrm{per} \mathrm{cm}^{2}$ of body self-shielding).

c. That the exposure is represented by the conditions in a parking orbit of $160^{\circ}$ west longitude. This is considered to be the worst case.

d. That no contribution to the total dose is made by solar particle events.

e. That the bulk of the dose is produced by trapped electron bremsitrahlung, and that the small contribution to the total dose made by galactic cosmic rays can be neglected.

f. That the time spent in GEO is 90 days per space tour.

The uncertainty in these assumptions is of an order that the dose estimate could vary by a factor of two.

\section{HEALTH RISK. ASSESSMENTS}

Using U.S. life tables of aqe and sex, the pstimated lifetime risk for cancer is 0.8 to 5.0 excess deaths per 10,000 workers per rad of exposure. Thus, for example, in 10,000 workers who completed ten missions with an exposure of 40 rem per mission, 320 to 2,000 additional deaths, in excess of the 1640 deaths from normally occurring cancer, would be expected. These estimates would indicate a 20 to 120 percent increase in cancer incidence in the worker-population. The wide range in these estimates stems from the choice of the riskprojection model and the dose-response relationship. The choice between a linear and a linear-quadratic dose-response model may alter 
the risk estimate for some tumors by a factor of at least two. The method of analysis (e.g., relative vs. absolute risk model) can alter the risk estimate by an additional factor of three. Choosing different: age and sex distributions can further change the estimate by another factor of up to three. When decisions have been made about the selection of SPS workers, the precise influence of age and sex distribution can be included in risk estimates. However, the choice of dose-respose relationship and projection models at present is a matter of opinion and.will not be resolved scientifically for quite some time.

\section{CONCLUSIONS}

The conclusions of the committee based on the findings above are:

a. The risk of excess cancer deaths is assumed to be closer to the lower limit estimated above because the major exposure will be from the low dose rate, low-LET irradiation. This being the case, we consider a reasonable estimate to be one excess death per 10,000 workers per rem of exposure. If this level of risk is applied to the worst case reference system exposure level, namely 40 rem, there would be 400 excess cancer deaths in a work force of 10,000 completing ten missions (accumulative dose equivalent of $400 \mathrm{rem}$ ).

b. The potential genetic consequences could be of significance, but at the present time, sufficient information on the age and sex distribution of the worker population is lacking for precise estimation of risk.

c. The potential teratogenic consequences resulting from radiation are considered significant. Radiation exposure of a pregnant worker could result in developmental abnormalities.

d. Based on the Reference System, dose to space workers from lowLET bremstrahlung approaches the cataratogenic level for man. The appropriate quality factor for the HZE particle portion of the dose is unknown at this time. If its $Q$ is greater than 20, the cataract hazard may be significant. More information is needed regarding this hazard.

e. In the absence of a radiation accident or some other unexpected situations (e.g., nuclear detonation) and with adequate shielding to protect against the increased radiation levels during solar particle events, there will be no early or acute radiation health effects occurring in the SPS worker population.

f. No other radiation health effects are considered to be of sufficient consequence to be important for risk estimation. 


\section{RECOMMENDATIONS}

This Committee strongly emphasizes the need to reduce the uncertainties in the evaluation of radiation health risks to SPS workers in the space environment. It recommends that the following be carried out to achieve these goals:

a. The short-term variations of the radiation dose rate in space must be better understood so that the range of doses and dose rates to be expected can be established accurately. A radiation environment model should be developed that is appropriate to this SPS mission for study and simulation. The model should include short-term and solar-cycle variations.

b. An instrumented research satellite should be placed in GEO to measure absorbed dose rate and particle spectra at depth in phantoms and to measure the temporal variations of the radiation field.

c. The differences in the results of dose and dose-rate estimation obtained from the shielding transport codes must be evaluated. The use of different calculational methods with the same set of assumptions should yield the same results.

d. When institutional decisions have been made to develop appropriate exposure strategies, engineering decisions for dose control (e.g., improved shielding) should then be made. 
1. INTRODUCTION

BACKGROUND

The need to develop long-term, baseload; electrical energy sources has initiated search for economically competitive and environmentally acceptable alternatives to our limited supply of fossil fuels and other nonrenewable energy sources. Such a search must consider the widest range of available and potential technologies. Satellite-based solar power generation has emerged as one possible source of electrical energy obtained from inexhaustible and renewable sources.

The U.S. Department of Energy (DOE) and the National Aeronautics and Space Administration (NASA) are examining the feasibility of generating baseload electrical power with Satellite Power Systems (SPS) located in geostationary orbit. These systems would collect radiant energy from the Sun, convert it to electrical energy, and then beam it to Earth as microwaves. Ground receiving stations would convert the microwaves to electrical energy to be supplied to power grids.

DOE and NASA are studying the large number of factors involved in bringing such a complex undertaking into being. At the present time, initial system definition studies have been completed. A Reference System (DOE/NASA, 1978) has been designed as a basis for further development and evaluation of important areas of uncertainty and for preliminary assessment of environmental impacts and potential health risks to SPS workers. This report directs attention to the radiation risks to the health of workers who will construct and maintain the SPS satellites in the space environment.

\section{THE SPACE ENVIRONMENT}

Man faces substantial risks to health in space. Prolonged periods in space can result in workers being exposed to radiation that can cause adverse health effects such as cancer, genetically related ill health, cataracts, and--with very large doses--even death. Exposure to ionizing radiations is a major factor in the evaluation of potential health risks to workers in space in the SPS program. Assessment of these health risks involves the determination of existing radiation dose levels. Methods must be developed to reduce radiation levels for persons in space to the lowest practical level. Determination must be made of the acceptable radiation levels which may not be absolutely safe but, rather, may be appropriately safe for the special circumstances of the space environment. 
Because SPS travel and work will take place in a number of different space environments--primarily low earth orbit (LEO): the transfer ellipse (TE), and geosynchronous earth orbit (GEO)--the worker in space will be exposed to radiation environments with different radiation qualities, varying intensities, and differing difficulty in predicting exposure levels. Assessment of potential health risks in each of the three. environments is influenced by many factors, including: (1) the location in space; (2) the type of shielding used in work stations, living quarters, transport systems, and space suits; (3) the types of duties performed; (4) the length of each mission; (5) the age and sex of space workers; and (6) the total number of missions per worker-career. This assessment of the radiation health hazards in space is 1 imited by the lack of adequate information concerning these factors and further complicated by inadequate data concerning the health effects of various types and dose levels of radiation on the human body.

The Reference System proposal is based on the following assumptions:

1. The SPS construction would occur mainly in GEO with all material transported from Earth.

2. There would be a two-phase transportation of materials and personnel: movement to LEO, followed by subsequent delivery to GEO.

3. After construction of the LEO base, cargo transportation vehicles for the voyage to GEO would be assembled in LEO.

4. The construction and operation of a fleet of 60 SPS facilities, assuming a 30-year lifet ime for each SPS, would require between 22,000 and 57,000 worker-years in space. The range of worker-years required takes into consideration the number of maintenance workers needed per SPS (from 4 to 20). The number of SPS workers required to achieve these goals would range between 10,000 and 20,000, with ten 90-day missions per worker.

5. The time spent in GEO would be between 87 and 98 percent of the total worker-years. 


\section{REFERENCE SYSTEM EVALUATION}

In determining potential radiation risks to the health of SPS workers in the space environment, an estimate must first be made of the radiation environment outside the space vehicle. This environment consists of trapped electrons and protons, galactic cosmic rays (GCR), and sporadic solar particle event (SPE). The average values of the flux densities of the primary radiation are presently known only to within a factor of two. The spacecraft and the space workers comprise a complex distribution of shielding materials which attenuates the primary radiation and which is also a source of secondary radiations. The transport of the radiation through the shield is fairly well understood, but there is uncertainty in the calculations due to assumptions of shield geometry and composition.

Dose estimates for previous space missions have been based on three-dimensional distribution of the shielding materials in the spacecraft and in the astronauts. Other calculations have been based upon solid-angle sectoring of the available shielding. All calculations for an SPS mission thus far have been made assuming simple geometries. Based on a recent analysis (Selzer, 1979), the absorbed dose calculated inside a spherical shell at a given radius is three to four times that at the same depth within a semi-infinite slab with isotropic radiation impinging on it from one hemisphere. For the purposes of this report, spherical shield geometry is therefore used to provide a worst case estimate of dose. However, this SPS Committee recognizes that until calculations for SPS radiation environments are based on more realistic shielding configurations, these calculations remain inadequate for detailed, accurate estimation of dose equivalent.

In this report, the shielding assumed is $3 \mathrm{~g} / \mathrm{cm}^{2}$ of aluminum for the habitat and work stations and $20-30 \mathrm{~g} / \mathrm{cm}^{2}$ for the storm cellar lo be used during solar particle events (SPE). The assumptions are based on the Boeing contribution to the Reference System (DOE/NASA, 1978). In addition, an average of $5 \mathrm{~g} / \mathrm{cm}^{2}$ of aluminum equivalent shielding is assumed for the body self-shielding in the present analysis. Thus, the estimates made below can be considered representative average doses at the center of a sphere of radius $8 \mathrm{~g} / \mathrm{cm}^{2}$ of aluminum equivalent material.

Because the relative biological effectiveness of the different radiations is variable, a quality factor $(Q)$ is assigned to each radiation, permitting calculations of a total dose equivalent (rem). The use of $Q$ is reasonable for biological endpoints of principal concern. However, there is the possibility that other health effects are caused only by high energy heavy ions (HZE particles). Therefore, at the present time, the use of a $Q$ for the HZE particles does not provide a complete assessment of the risk to health of SPS workers. 
ESTIMATED ABSORBED DOSES AND DOSE EQUIVALENTS IN SPS WORKERS

Low Earth Orbit

Dose estimates are most accurate for the LEO phase of the mission. Protons in the South Atlantic Anomaly pose the only major source of external radiation. The dose equivalent in LEO will vary by about a factior of two between solar minimum and solar maximum (Stassinopoulos, 1979). The dose rate estimates at solar minimum, when the doses are higher, range from 0.15 rad per day (Hardy, 1979) to 0.3 rad per day, the latter value corrected from a semi-infinite slab calculation (Stassinopoulos, 1979) to spherical shielding (Seltzer, 1979). Since $Q$ for this radiation is close to unity, these values are good estimates of the dose equivalent rate in rem per day. There will be a negligible contribution to the dose from galactic cosmic rays and solar particle events, due to the large amount of geomagnetic shielding available in the LEO trajectory. The total dose equivalents for a 90-day mission in LEO are therefore estimated to be between 14 and 28 rem at solar minimum and between 7 and 14 rem at solar maximum.

Transfer Ellipse

Dose calculations have been made for the 5.25 hour transfer ellipse from LEO to GEO. These results vary between 1.0 rad (Hardy, 1979) due primarily to protons, and 0.018 rad (Stassinopoulos, 1979) due primarily to bremsstrahlung. As is the case for LEO, the se are the estimates for the dose equivalents in rem as well. The large difference is the result of different assumptions in the trajectory made for the calculations.

\section{Geosynchronous Orbit}

In GEO, a majority of the absorbed dose is due to bremsstrahlung produced by the trapped electrons. An estimate of the dose equivalent for a worst case exposure from predictable radiation is 0.43 rem per day inside an aluminum sphere with radius $8 \mathrm{~g} / \mathrm{cm}^{2}$ (Seltzer, 1980).

The contribution to the dose equivalent by the galactic cosmic rays (GCR), particularly from the heavy charged particle component, may be important. The fragmentation characteristics of the heavy particle component must be considered for an accurate estimation of the absorbed dose from GCR (Wilkinson and Curtis, 1972). The quality factors (Q) necessary to convert absorbed dose to dose-equivalent are yenerally unknown for these radiations. Using a $Q$ of 3 for the GCR, independent of depth, yields a very rough estimation of the dose equivalent as a function of depth. Use of an average value for $Q$ of 3 for the galactic cosmic ray contribution is consistent with current recommendations (ICRP 26, 1977). Q values are under continual reassessment, and it is 
possible the $Q$ value could be increased for the HZE particle contributions. This Committee believes that an average $Q$ of 3 may not be conservative for carcinogenic or mutagenic effects produced at low doses and low dose rates over long periods. This is a simplified model and more must be learned about the variation of $Q$ with dose and depth for the GCR before a more accurate value for the dose equivalent can be obtained.

The shielding of manned space vehicles against the proton and helium ion component of the GCR has been examined (Santoro et al., 1973). The absorbed dose and dose equivalent due to primary particles and to secondary particles arising from the self-shielding of the tissue sphere are little affected by increasing the sphere radius from 5 to $20 \mathrm{~g} / \mathrm{cm}^{2}$ of aluminum. Protons and helium ions and their associated secondary radiations contribute about 55 to 65 percent to the total galactic cosmic ray dose and a smaller percent to the total dose equivalent. The dose and dose-equivalent rates for the combined proton and helium ion components average $31 \mathrm{mrad}$ per day and $73 \mathrm{mrem}$ per day, respectively, yielding an average $Q$ of 2.4. This value of $Q$ is a lower limit when the HZE particle contribution is very small. If the $Q$ of 2.4 is the value for the proton and helium ion components, the average for all components may be higher than the $Q$ value of 3 assumed above.

Solar particle events (SPE) will be a major hazard in GE0; special shielding--a storm cellar--is needed for space workers during a solar particle event. The dose received from a given SPE will depend upon the size of the SPE, the length of time of the warning before the particle buildup, the time required for the workers to get inside the storm cellar and the storm cellar shielding thickness. The size and time of occurrence of an SPE are not currently predictable. It is known that a correlation exists with the sunspot number and that the event frequency has an 11-year cycle. Within this cycle, there is a three- to five-year period that is almost event free. During the remaining six to eight years of the period, there is about a 40 percent probability of a large SPE each year. The total dose from the solar particles within the 11-year cycle is generally dominated by the contribution of the largest event within the cycle. This makes the accuracy of the prediction of size of an event that is about to occur, or is just starting, very important because of the special precautions which must be taken.

For a $30 \mathrm{~g} / \mathrm{cm}^{2}$ tissue sphere, the wilson and Denn (1976) calculations provide a dose equivalent of an additional 2.5 rem for an SPE with the size and energy spectrum of the August 1972 event and 25 rem for the February 1956 event (Fig. 1). Webber (1963) made a similar estimate for the 1956 event. Rossi and Stauber (1977) estimated the dose equivalent behind $40 \mathrm{~g} / \mathrm{cm}^{2}$ of aluminum (equivalent to about $30 \mathrm{~g} / \mathrm{cm}^{2}$ of tissue) to be 25 rem for the August 1972 event, a factor 


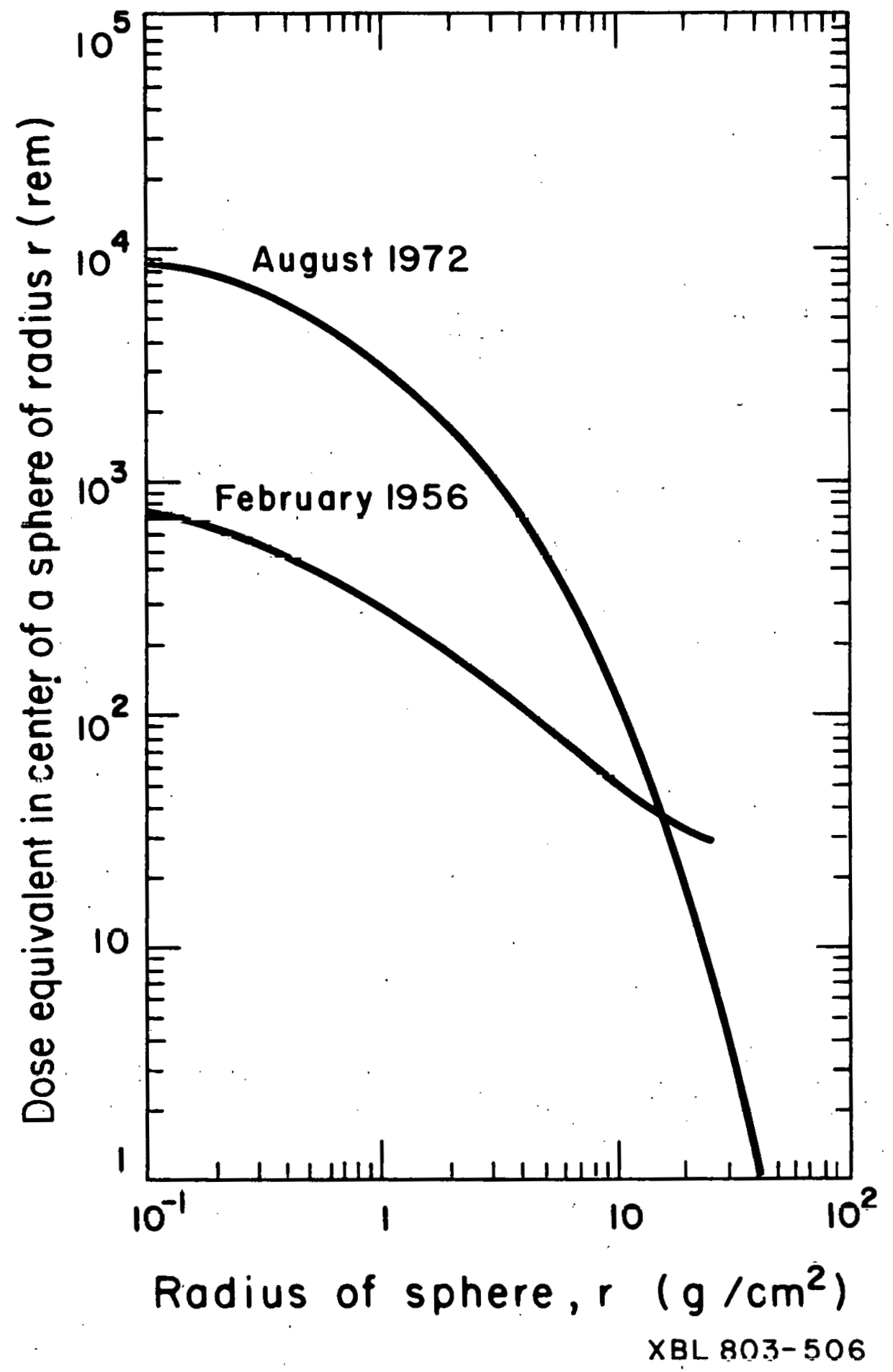

Figure 1. Dose equivalents from two major solar particle events (SPE) plotted as a function of the radius of tissue equivalent sphere. Adapted from Wilson, 1979. 
of ten greater than the Wilson and Denn (1976) calculations. These differences in dose calculations for the 1972 event are still to be resolved.

\section{Total 90-Day Dose Equivalent}

Daily dose equivalents in the three phases of the SPS mission are summarized in Table 1. From the table, the best estimate of dose equivalent from predictable radiation sources at the worst parking orbit is approximately 40 rem for 90 days in GEO, assuming a $Q$ value of unity. This dose equivalent value is derived from the calculations of Seltzer (1980) for a geostationary orbit with an altitude of $35,790 \mathrm{~km}$, an inclination of $0^{\circ}$, and a parking longitude of $160^{\circ} \mathrm{W}$, the worst condition for radiation exposure to trapped electrons (Stassinopoulos, 1980). The incident electron spectrum was integrated for the epoch 1979.0 using the AEI7-HI environmental model. This model is based on a recent compilation of trapped electron data yielding conservatively high average values for the flux densities. A total spherical shield of $8 \mathrm{~g} / \mathrm{cm}^{2}$ aluminum equivalent material $\left(3 \mathrm{~g} / \mathrm{cm}^{2}\right.$ of spherical spacecraft shielding plus $5 \mathrm{~g} / \mathrm{cm}^{2}$ effective body selfshielding) is assumed to obtain the above value of the absorbed dose in water. The shape of the dose vs depth curve is such that a 50 percent change-in the total shield assumed will affect the volume of the dose by a factor or two.

The largest contribution to the dose equivalent is the bremsstrahlung. In addition, there is about a 10 percent probability of an additional 2.5 rem from solar particle events, and a smaller probability that the SPE dose equivalent might be as high as 25 rem. A smaller contribution will be made by GCR. Therefore, the worst case 90-day mission dose equivalents will most likely be within the range of 40 rem (no SPE) to 65 rem (with large SPE). The Committee emphasizes that these are preliminary dose-equivalent estimates with large uncertainties.

\section{ASSESSMENT OF RISK FOR CANCER INDUCTION}

This SPS committee considered radiation-induced cancer the major health risk associated with exposure to ionizing radiations at dose levels most likely to be encountered in the SPS space environment. The risks can be calculated based on the whole-body exposure and a linear-quadratic dose-response model (NAS-BEIR, 1980), and average career dose-equivalent values may be used. As an illustrative example, 
Table 1. Estimated dose equivalents at the center of an aluminum sphere of $8 \mathrm{~g} / \mathrm{cm}^{2}$ radius for the three phases of SPS*.

Mission phase

Dose equivalent (rem)

Reference

LEO:

Average datiy dose equivalent

0.15

0.30

$\sim 1$

$\sim 0.2$ LEO to GEO at solar minimum

A. Hardy, 1979

Stassinopoulos, 1979 modified to spherical shields (Seltzer, 1979)

$T E$ :

Average one way trip from

Hardy, 1979

-

0.43

Seltzer, 1979

* A $Q$ of unity is assumed for the conversion from the absorbed dose to dose equivalent.

at solar minimum (excluding

solar particle events)

assuming a "worst" case

longitude of $160 \mathrm{~W}$.

Stass inopoulos, 1979 modified to spherical shields (Seltzer, 1979)

GE0:

Average daily dose equivalent

\author{
cquivalent.
}


among 10,000 SPS workers from the general population of all age groups, about 1,640 persons would be expected to die of cancer, in the absence of any additional radiation exposure. Based on the dose-equivalent estimate in GEO for the Reference System design (40 rem per 90-day mission) and ten missions per career (accumulated dose equivalent of $400 \mathrm{rem}$ ), the linear-quadratic dose response model predicts increases of between 20 and 60 percent depending on the projection model (about 160 to 1,000 excess cancer deaths). The linear dose-response model predicts values about two times larger.

Such cancer risk predictions are subject to a large number of uncertainties, as outlined in this report. In spite of these uncertainties, this SPS Committee concludes that the increased potential in cancer-induction risk due to radiation exposure in the SPS environment, as presently envisaged with the present Reference System design, can be substantially reduced.

There is also the possibility that this radiation might increase genetically-related ill health, developmental abnormalities in the newborn, lens cataracts, and temporarily decrease fertility. If the radiation dose is substantially reduced, as suggested above for the purpose of reducing cancer incidence, the probability of these other health risks will also be reduced.

Additional details regarding the space radiation environment and radiation health effects are given in Appendices $A$ and $B$. 


\section{3.. CONCLUSIONS AND RECOMMENDATIONS}

\section{HEALTH RISK ASSESSMENTS.}

For ionizing radiation, the major concern will be late or delayed health effects, particularly the increased risk of radiation-induced cancer. The estimated lifetime risk for cancer is 0.8 to 5.0 excess deaths per 10,000 workers per rad of exposure. Thus, for example, in 10,000 workers who completed ten missions with an exposure of 40 rem per mission, 320 to 2,000 additional deaths in excess of the 1640 deaths from normally occurring cancer, would be expected. These estimates would indicate a 20 to 120 percent increase in cancer deaths in the worker-population. The wide range in these estimates stems from the choice of the risk-projection model and the dose-response relationship. The choice between a linear and a linear-quadratic dose-response model may alter the risk estimate by a factor of about two. The method of analysis (e.g. relative vs absolute risk model) can alter the risk estimate by an additional factor of three. Choosing different age and sex distributions can further change the estimate by another factor of up to three. When decisions have been made about the selection of SPS workers, the precise influence of age and sex distribution can be included in later risk estimates. However, the choice of dose-response relationship and projection models is a matter of opinion and will not be resolved scientifically for quite some time.

\section{CONCLUSIONS}

The conclusions of the committee based on the findings above are:

1. The risk of excess cancer deaths will be closer to the lower limit estimated above because the major exposure will be from low dose rate, low-LET irradiation. This being the case, we consider a reasonable estimate to be one excess death per 10,000 workers per rem of exposure. If this level of risk is applied to the worst case reference system exposure level, namely $40 \mathrm{rem} / \mathrm{mission}$, there would be 400 excess cancer deaths in a work force of 10,000 completing ten missions (accumulated dose equivalent of $400 \mathrm{rem}$ ).

2. The potential genetie consequenees, which vary with the popula= tion age distribution, could be of significance. At the present time, sufficient information on the age and sex distribution of the worker population is lacking for precise estimation of impact.

3. Similarly, the radiation exposure of a pregnant worker could lead to developmental abnormalities in the embryo. 
4. Based on the Reference System (estimated 400 rem from ten missions), dose to space workers from low-LET bremstrahlung approaches the cataractogen ic level for man. The appropriate quality factor of the HZE particle portion of the dose is unknown at this time. If its $Q$ is greater than 20, the cataract hazar.d may be significant. More information is needed about the cataractogenic risk of exposure to high-LET radiations.

5. With adequate information on the radiation environment, with well-designed areas protected from the increased levels during solar particle events, and in the absence of a radiation accident or some other unexpected situations (e.g., nuclear detonation), there will be no early or acute radiation nealth effects occurring in the SPS worker population.:

6. No other radiation health effects are considered to be of sufficient consequence to be important for risk estimation.

\section{RECOMMENDATIONS}

The SPS Committee strongly emphasizes the need to reduce the uncertainties in the evaluation of radiation health risks to SPS

workers in the space environment. It recommends that the following be carried out to achieve this goal:

1. A radiation environment model, appropriate to this SPS mission, should be developed for study and simulation. The model should include short-term and solar-cycle variations. The short-term variations of the radiation dose rate in space must be better understood so that the range of doses and dose rates to be expected can be established accurately.

2. An instrumented research satellite should be placed in GEO to measure absorbed dose rate and particle spectra at depth in phantoms and to measure the temporal variations of the radiation field.

3. The differences in the results of dose and dose-rate estimation obtained from the shielding transport codes must be evaluated. The use of different calculational methods with the same set of assumptions should yield the same results.

4. When institutional decisions have been made to develop appropriate exposure strategies, engineering decisions for dose control should then be made.

5. Radiation shielding of transport vehicles, work stations, habitats, and space suits should be designed to achieve minimal radiation exposure levels. The use of laminar layering, where 
possible, to reduce the dose and dose rate from bremsstrahlung to the lowest practical values provides a practical example.

6. Studies should be initiated promptly to define the space worker population profiles, particularly the age and sex distributions. Age-specific deaths rates from all causes, in general, and cancers, in particular, should be obtained for a worker population composition similar to that which will work in space. These studies on the SPS worker populations will then provide the data base for calculations of potential health risks of ionizing radiations in the space environment.

7. The biological effects of the HZE particle radiations must be investigated in detail in order to determine appropriate quality factors and risks from lesions unique to HZE. Interactions between high- and low-LET radiation that could occur in the spare radiationn envirnnment. shnuld he considered, particularly the possibility of synergistic effects. on carcinogenesis or mutagenesis.

8. The health effects of exposure to low-level ionizing radiations must be considered in the context of the potential health effects of other physical and chemical agents in the space environment. Such competing effects may interact with other host or constitutional factors to mask, enhance, or diminish any radiation health effects, such as cancer. Environmental factors to be considered include cabin atmosphere, temperature and pressure, nutrition, non-ionizing radiation and weightlessness.

This SPS Committee concludes that the radiation environment estimated for the Reference System represents a health risk to SPS workers. However, the Committee emphasizes that none of the problems identified are considered sufficiently intractable to preclude achieving a minimal risk to SPS workers.

A number of areas have been considered which we believe impact on the potential health effects on workers in space. These include, for example: the biological effects of HZE particles; the effects of environmental agents in space, other than ionizing radiation, which may affect the radiation health effects; and the RBE/LET relationships. However, much more needs to be known about these tactors before they may be used to improve the accuracy of quantitative estimation of health risks in space. The Committee has chosen not to include these uncertainties in its estimations at the present time but urges increased studies in these areas to provide greater precision for future SPS health assessments. 
APPENDIX A

\section{SPACE RADIATION ENVIRONMENT}

The preliminary SPS Reference System (DOE/NASA, 1978) calls for workers to move from Earth to low Earth orbit (LEO) (aititude $500 \mathrm{~km}$ ) for stays of varying lengths of time. Workers then travel to geosynchronous Earth orbit (GEO) (altitude about $36,000 \mathrm{~km}$ ), following an elliptical trajectory (transfer ellipse, TE). These three SPS environments--LEO, TE, and GEO--have ionizing radiations of different quality, time dependence, and predictability of dose levels. The various components of the radiation environment are described in this section, and those important to each SPS stage are identified.

\section{TRAPPED ELECTRONS}

Large flux densities of electrons, trapped in the earth's magnetic field, are contained in an inner and outer zone separated roughly by the magnetic shell parameter, $* L=2.8$ earth radii. The low energies of electrons in the inner zone are important only if persons are protected by very thin shielding ( $<0.5 \mathrm{~g} / \mathrm{cm}^{2}$ aluminum) (Stassinopoulos, 1979). The outer zone contains flux densities of electrons which are greater in magnitude than those of the inner zone and have a.larger fraction of high-energy particles. Maximum flux densities occur in the region of about 3.5 earth radi $i$ (approximately $21,300 \mathrm{~km}$ ); the trapping region extends out to about 12 earth radii $(76.540 \mathrm{~km})$. Space vehicles transporting workers and materials from LEO must travel through the heart of the outer electron zone to reach GEO which, at 6.6 earth radii, is well with in the outer zone of trapped electrons. Figure A-1 illustrates the spatial variation of trapped electrons as a function of altitude and geographic latitude, the positions of LEO and GEO, and a representative pass for the transfier trajectory (TE).

Two large temporal variations of the outer zone electron flux densities at the position of a GEO satellite have been identified (Stassinopoulos, 1980):

1. Diurnal variations--At GEO, electron flux dellsities vary over factors between 6 and 16 (depending on $L$ value) between day and night. The maxima occur at about 1000 to 1100 hours, and the minima at about 2200 to 2300 hours, local time. The extent and. times of these extremes also depend on electron energy and, to a small degree, on position in the eleven-year solar cycle.

\footnotetext{
*The magnet shell parameter, $L$, denotes roughly a geomagnetic field line. The value gives the approximate geocentric distance, in earth radii, of the intersection of the field line with the geomagnetic equatorial plane.
} 


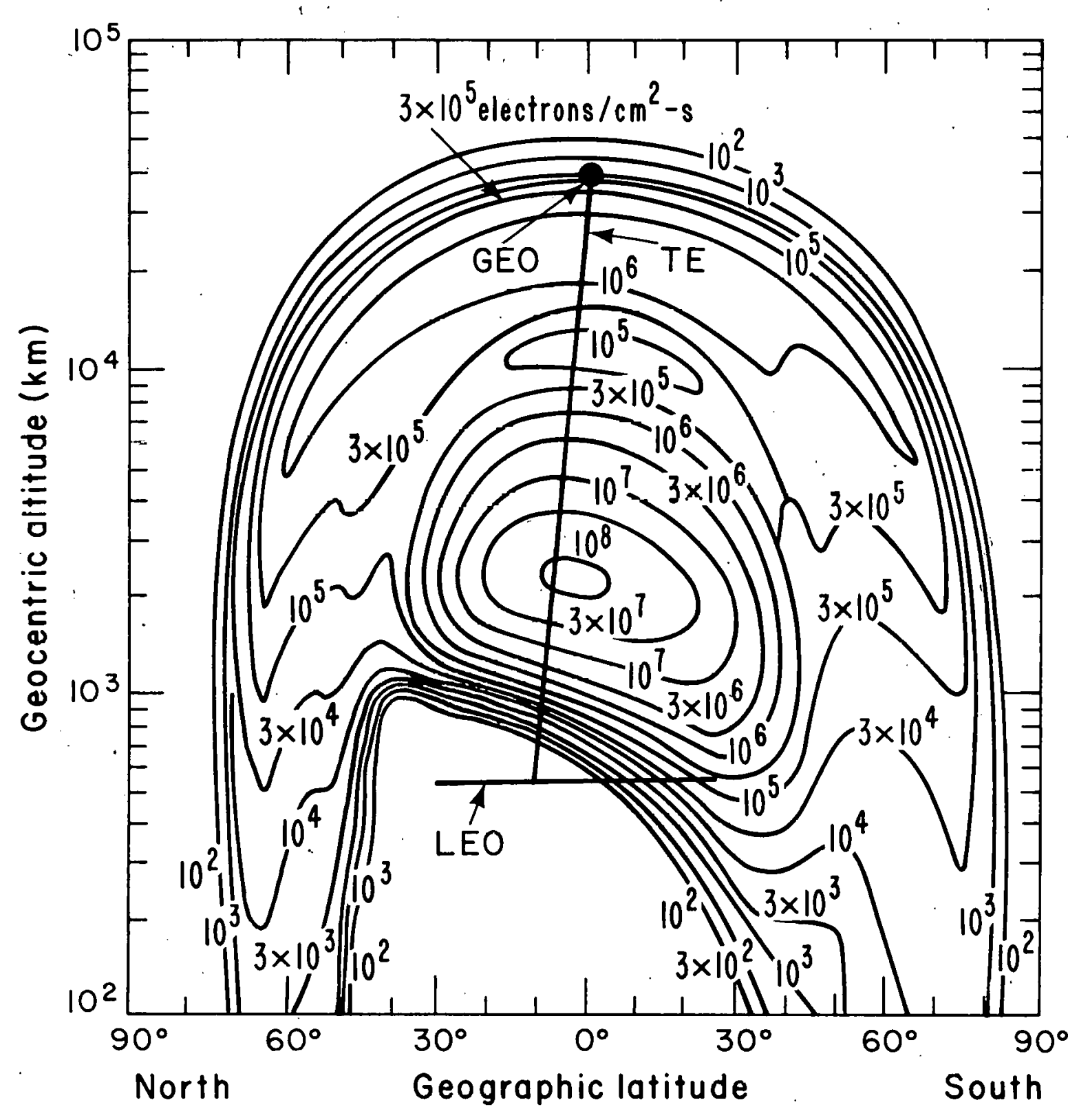

$X B L 803-507$

Fiyure A-1. The spatial variation of trapped electrons, plotted as a function of altitude and gengraphic latitude. The positiuns of LEO, GEO, and a representative pass for the trinsfer Lrajectory are illustrated. Adapted from Wilson, 1979. 
2. Short-term ennancements--Electron flux densities can increase markedly due to intermittent changes in the solar plasma associated with small substorms. Flux densities may rise two to three orders of magnitude in several hours followed by a decay lasting several days (Stassinopoulos, 1980).

\section{BREMSSTRAHLUNG}

In general, the absorbed dose from bremsstrahlung is not dominant behind thin shielding (e.g., $<3 \mathrm{~g} / \mathrm{cm}^{2}$ aluminum) because of the overriding preponderance of primary electrons. However, at greater depths, the dose from electrons drops sharply, dependent largely on the shape of the incident electron energy spectrum. This causes the bremsstrahlung to dominate the absorbed dose at large shielding thicknesses, (e.g., $>3 \mathrm{~g} / \mathrm{cm}^{2}$ aluminum). For inner zone electrons at LEO, the bremsstrahlung dose is completely dominated at all thicknesses by the dose from trapped protons (see below). Here, the bremsstrahlung dose is sufficiently small to be negligible. For outer zone electrons at GEO, on the other hand, the bremsstrahlung dose dominates behind shielding of $3 \mathrm{~g} / \mathrm{cm}^{2}$ aluminum or greater thickness (Stassinopoulos, 1980). Thus, the bremsstrahlung dose is an important component of the radiation environment in GEO and in the transfer ellipse between LEO and GEO, taking into account certain assumptions of trajectory and vehicle speed.

\section{TRAPPED PROTONS}

Protons are also trapped in large numbers by the geomagnetic field. A region of the trapped proton zone dips close to the earth in the southern Atlantic Ocean, southeast of the Brazilian coast. This rogion, called the South Atlantic Anomaly, is the most important contributor to the radiation environment for space workers in LEO. A spacecraft in LEO, however, will pass through this region on only 60 percent of its revolutions. Stassinopoulos (1979) has estimated that 86 percent of the time in LEO is flux-free, i.e., in a radiation environment. of less than one particle $/ \mathrm{cm}^{2}-\mathrm{sec}$ of electrons with energies greater than $0.5 \mathrm{MeV}$ and protons with energies greater than $5 \mathrm{MeV}$. Each day, for a maximum duration of ten hours, there are about six consecutive flux-free revolutions without danger of increased radiation exposure.

Trapped protons may be important in the TE between LEO and GEO, depending on the trajectory and vehicle speed selected. Two different calculations of the proton environment encountered by a transfer vehicle have been made, assuming proton environments varying by several orders of magnitude (see "Transfer Ellipse," p. 8). In GEO, the trapped protons are of such low energy that they will not present a health risk to workers at nominal shielding thicknesses. 
Galactic cosmic radiation consists primarily of high-energy nuclei with origins outside our solar system; these particles appear to pervade regions outside our magnetosphere isotropically. Approximately 88 percent are protons, 10 percent are helium nuclei, 1 percent are electrons, and 1 percent are heavy nuclei $(Z>2)$. Ratios of abundances relative to carbon $(Z=6)$ are shown for the heavy nuclei as a function of nuclear charge number or $Z$ in Fig. A-2. If each nuclear species has a similariy shaped energy spectrum, the relative absorbed dose in free space in a small sphere of tissue from each species would be the GCR abundance ratios scaled by $Z^{2}$. Due to differences in the spectral shapes at low energies, there are variations noted from the simple $Z^{2}$ scaling. However, the difference at low energies is important only behind thin shielding.

Table A-1 presents three calculations of the estimated absorbed dose rate in a small tissue sphere in free space and the relative composition from particles grouped in broad ranges of $Z$ (Curtis, 1974). The first two calculations (Curtis and Wilkinson, 1968; Schaefer, 1968) were obtained by integration of the appropriate energy spectra. 'The third calculation was based on experimental data from a balloon at high altitude (Anderson, 1968). The daily dose rate of between 30 and $40 \mathrm{mrad} /$ day is the maximum expected, since the spectra used were appropriate for solar minimum when the galactic flux densities are known to be the highest. The daily absorbed dose within the body will be less than this value because, although the dose from the protons will not decrease with depth, there will be a decrease in the contribution from the heavier components (see Section 2).

Curtis (1973) calculated that the flux densities of HZE particles with LET > $100 \mathrm{keV} / \mathrm{\mu m}$ decrease from 8 to $3 \mathrm{~cm}^{2} \mathrm{hr}$ as the shielding is increased from 1 to $10 \mathrm{~g} / \mathrm{cm}^{2}$ of aluminum. Approximately. 65 percent of the particles with charge greater than two have charges in the range of $20-26$, and this percentage does not vary significantly with thickness of shielding.

Measurements made on Soviet satellites Prognoz 1 and Prognoz 2 over an eight month period in 1972, during quiet radiation conditions outside the magnetosphere, yield an estimated dose-rate of about $24 \mathrm{mrad} /$ day (Logachev et al., 1974). The estimated dose rate is about $10 \mathrm{mrad} /$ day at solar maximum. Data from U.S. Satellites Mariner II and Mariner IV from late 1962 to 1964 provide estimated dose-rate values of 30 to $45 \mathrm{mrad} / \mathrm{day}$ at solar minimum. Pinneer IV measurements correspond to dose rates of about 9.6 and $24 \mathrm{mrad} / \mathrm{day}$, the latter at solar minimum (Janni and Holly, 1969). Pioneer $V$ data yield an estimated dose rate value of about $14.4 \mathrm{mr} a d /$ day at solar maximum. These estimates are summarized in Table $A-2$. 


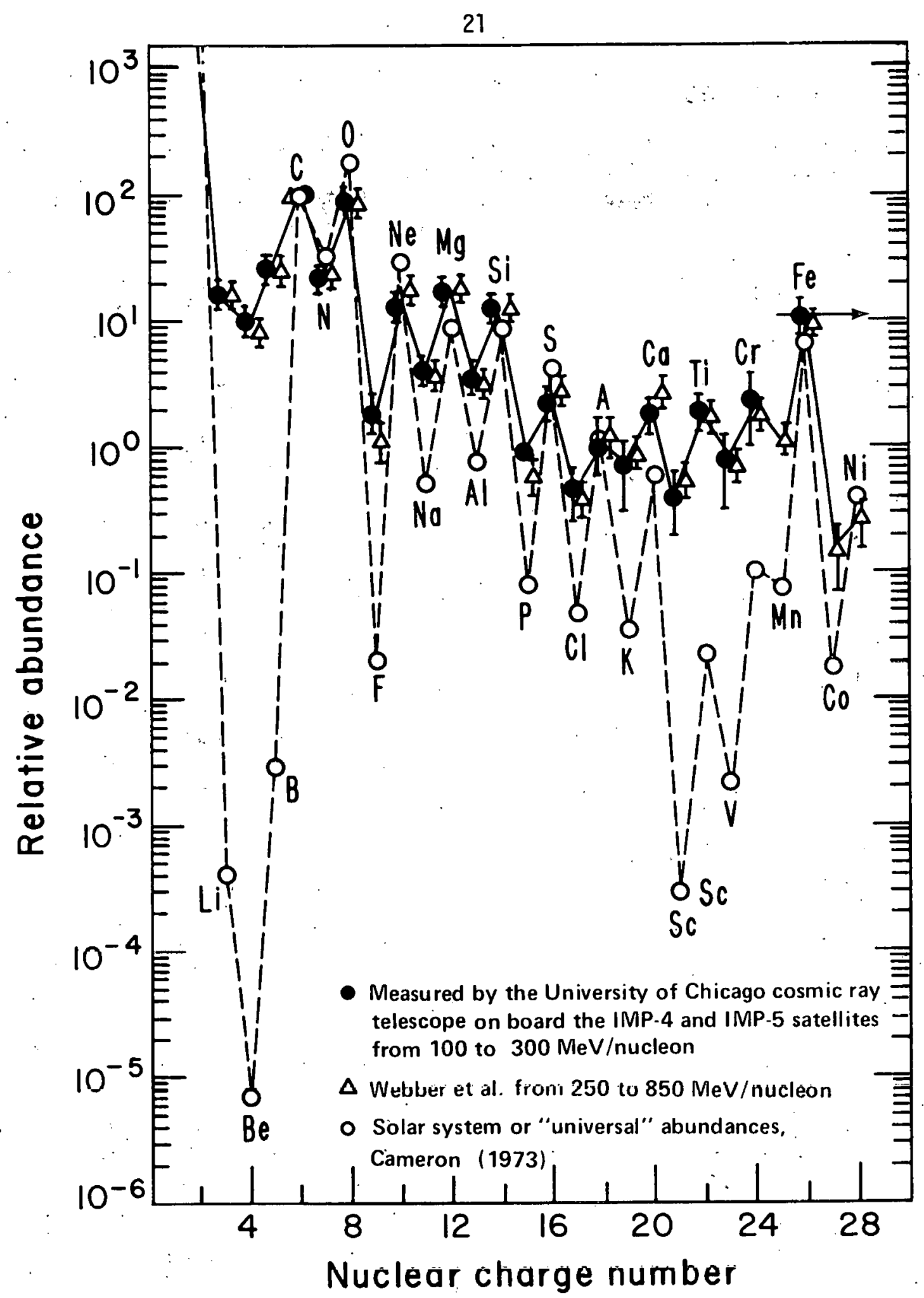

XBL 803-508

Figure A-2. Comparison of the abundances of the elements in galactic cosmic rays with the solar system abundances. Adapted from Wefel, 1979. 
Table A-1. Primary galactic cosmic-ray dose rates at solar minimum*.

\begin{tabular}{|c|c|c|c|}
\hline Reference & $\begin{array}{l}\text { Dose-rate } \\
\text { (mrad/day) }\end{array}$ & $\begin{array}{l}\text { Charge } \\
(Z)\end{array}$ & $\begin{array}{c}\text { Relative Composition } \\
\text { (\% of total dose) }\end{array}$ \\
\hline $\begin{array}{l}\text { Curtis and } \\
\text { wilk inson, } \\
1968\end{array}$ & . . . & $\begin{array}{c}1 \\
2 \\
6-9 \\
10-14 \\
26-28\end{array}$ & $\begin{array}{l}37 \\
28 \\
15 \\
10 \\
10\end{array}$ \\
\hline Schaefer, 1968 & 30.6 & $\begin{array}{r}1 \\
2 \\
6 \\
10 \\
20\end{array}$ & $\begin{array}{r}40 \\
24 \\
15 \\
9 \\
12\end{array}$ \\
\hline Anderson, 1968 & $\sim 42.5 \pm 4.3$ & $\begin{array}{c}1 \\
2 \\
>2 \\
\text { Electrons }\end{array}$ & $\begin{array}{r}32 \\
25 \\
38 \\
5\end{array}$ \\
\hline
\end{tabular}

* Curtis, 1974 . 
Table A-2 Comparison of measured radiation dose-rates in space satellites.

\begin{tabular}{|c|c|c|}
\hline Satellite & $\begin{array}{l}\text { Dose Rate } \\
\mathrm{mrad} / \text { day }\end{array}$ & Comment \\
\hline \multirow[t]{2}{*}{$\begin{array}{l}\text { Prognoz } 1^{a} \\
\text { Prognoz } 2\end{array}$} & 24 & $\begin{array}{l}\text { Measured at quiet radiation } \\
\text { conditions outside magneto- } \\
\text { sphere }\end{array}$ \\
\hline & 10 & Estimated at solar maximum \\
\hline $\begin{array}{l}\text { Mariner II } \\
\text { Mariner IV }\end{array}$ & $30-45$ & Measured at solar minimum \\
\hline Pioneer IVb & 24 & $\begin{array}{l}\text { Measured at solar maximum } \\
\text { Measured at solar minimum }\end{array}$ \\
\hline Pioneer V & 14.4 & Measured at solar maximum \\
\hline \multicolumn{3}{|c|}{ a Logachev et al., 1974} \\
\hline
\end{tabular}




\section{SOLAR PARTICLE EVENTTS"}

Giant solar particle events (SPE) are caused by large upheavals on the solar surface which accelerate protons and, to a lesser extent, heavier nuclei to high energies. These particles are then transported through the solar magnetic field and can increase radiation levels to high values for several hours or days in the vicinity of the earth outside our magnetosphere. GE0, at 6.6 earth radii, is in such minimal geomagnetic shielding that particles down to very low energy arriving in the vicinity of the earth will be able to reach it.

Large events occur with highest probability during the rising or falling portions of the eleven-year solar activity cycle. A very small number of events have dominated the total fluence of particles arriving in an eleven-year period. Figure A-3 shows that the events occurring in August 1972 dominated the total fluence arriving in cycle 20 and compares these events with others which occurred in'1967, 1969, and 1971. In Figure A-4, two different estimates of the dose equivalent at the center of a sphere of radius $r$ from the August 1972 event are plotted as a function of the radius; a discrepancy exists between the two calculations, and this is still to be resolved. The figure shows, however, that the sphere radius must be at least $10 \mathrm{~g} / \mathrm{cm}^{2}$ of tissue before the dose equivalent drops below 100 rem. The occurrence of such large events, therefore, results in high dose-rate exposures which will be a considerable radiation hazard to SPS workers in GEO." For workers in LEO, on the other hand, enough shielding is provided by the geomagnetic field to make dose equivalents from solar events negligible..

\section{DIFFERENT EFFECTS OF HIGH- AND LOW-LET RADIATIONS}

In the evaluation of the potential health effects caused by space radiations, the radiations may be divided into general categories based on linear energy transfer (LET) or collision stopping power. Low-LET radiations, such as nigh energy electrons and protons, have ionizations which are relatively far apart, with only a small probability of interaction between the ionization products created by a single ionizing particle. Those interactions which do occur are primarily the result of multiple particle tracks. High-LET radiations, such as heavy charged particles, are characterized by ionizations which are normally more closely spaced, and there is therefore a correspondingly greater probability of interactions between the ionization products created by the passage of a single particle. This difference in the microscopic dose distribution generally causes the higher LET radiations to have a greater biological effectiveness.

\section{QUALITY FACTOR}

A quality factor, $Q$, has been defined to account for the varying degrees of potential adverse health effects in man caused by different 


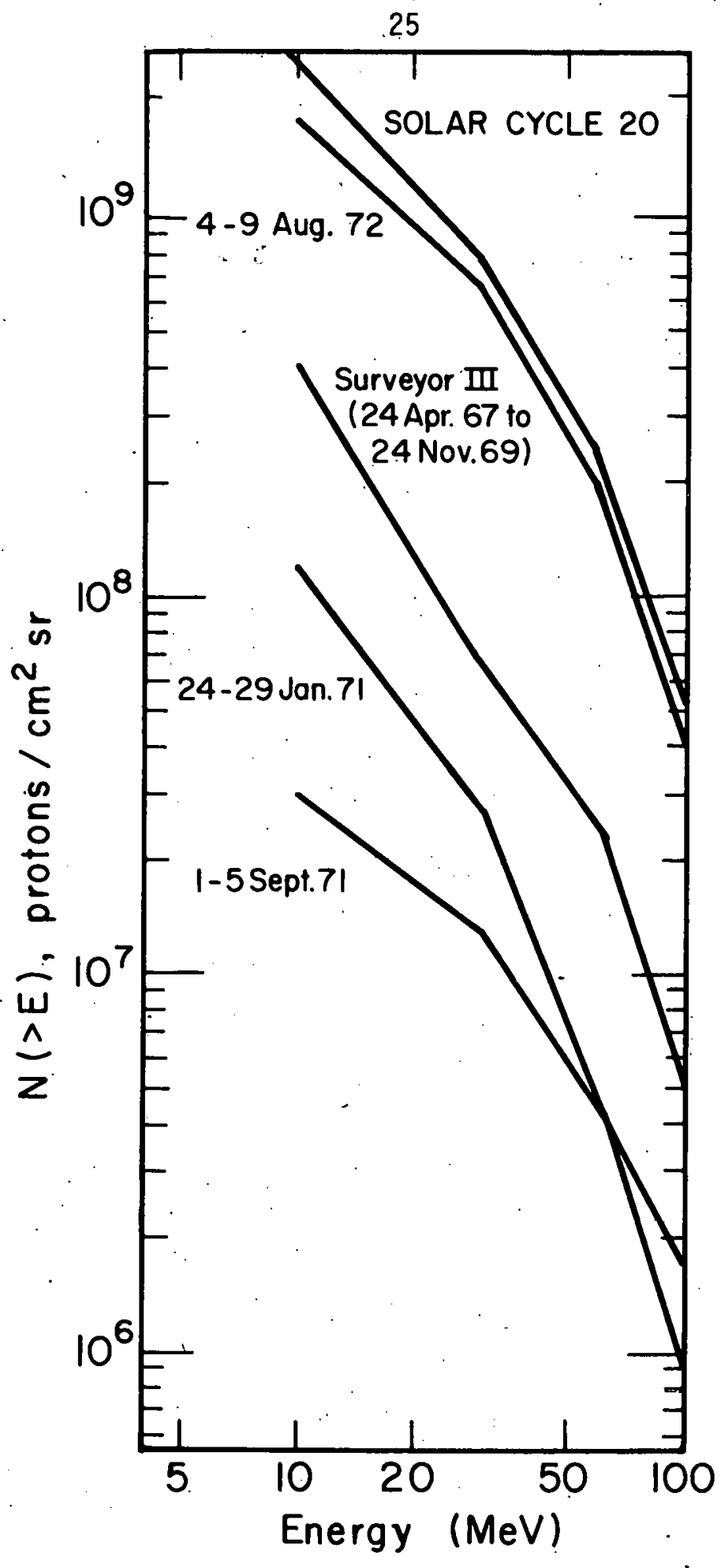

XBL759-4570

Figure A-3. Degree of domination of total fluence arriving in cycle 20 by solar events which. occurred on 4-9 Auyust 1972. Ndapted from Crawford et al., 1975. 


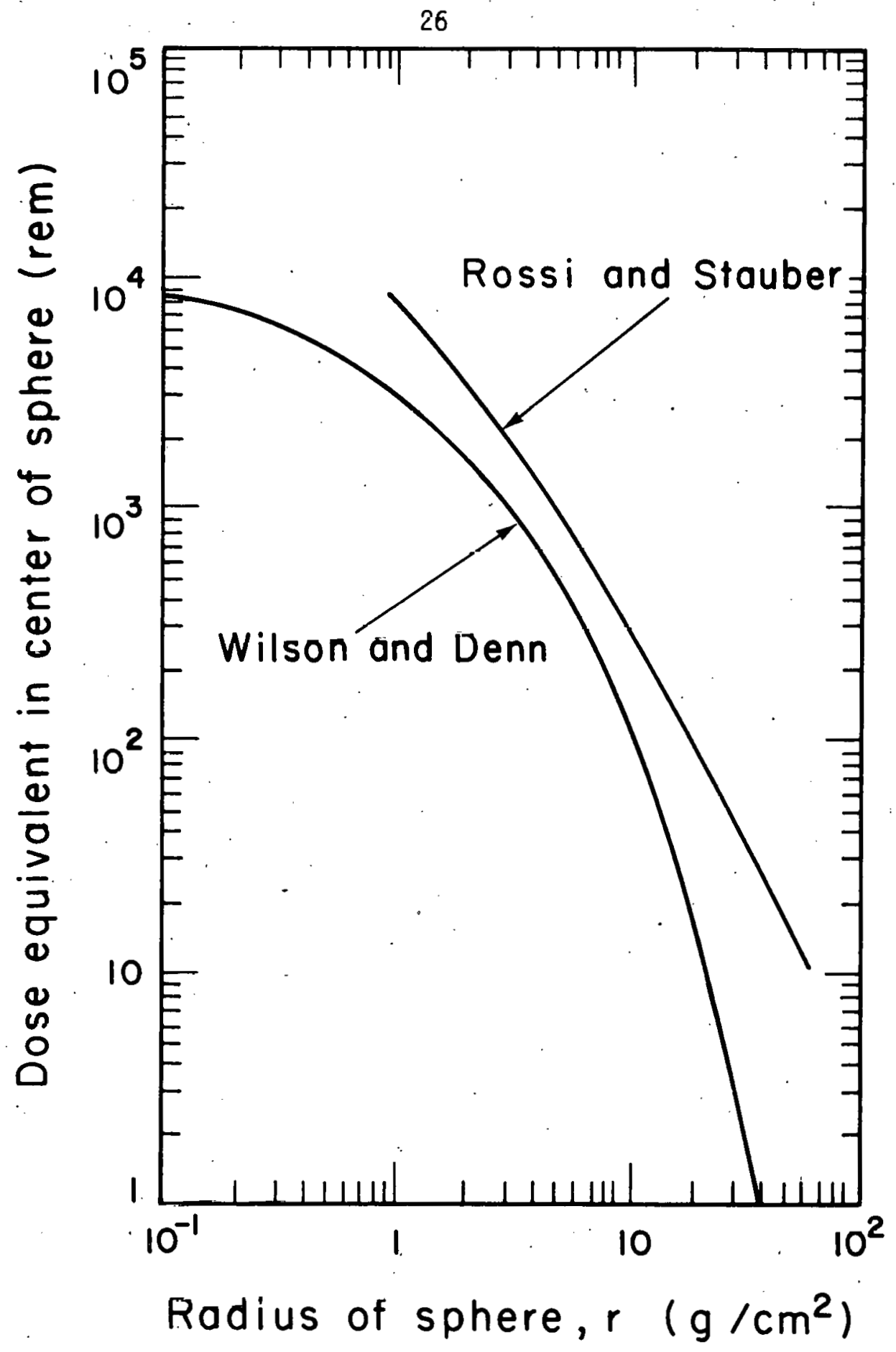

\section{XBL $801-161$}

Figure A-4. Dose equivalents from the August 1972 solar event at the center of a sphere as calculated by Rossi and Stauber (1977) and Wilson and Denn (1976). 
ionizing radiations of different LET (ICRP 26, 1977). Currently recommended quality factors vary from 1 (for radiations with LET equal to or less than $3.5 \mathrm{keV} / \mathrm{\mu m}$ ) to 20 (for radiations with LET equal to or greater than $175 \mathrm{keV} / \mu \mathrm{m})$. These values have been selected on the basis of relevant low dose and/or low dose-rate RBE values. They have guided our estimation of a quality factor for the galactic cosmic radiation. $Q$ values are used for assessing radiation health effects for radiation protection purposes, and not to assess the potential health effects of severe accidental high-dose exposures.

There may be some health effects caused only by HZE particles and not by other radiations, and here the conventional use of a quality factor does not provide an assessment of potential health risks. 


\section{APPENDIX B}

\section{RADIATION HEALTH EFFECTS IN THE SPACE ENVIRONMENT}

Radiation doses and dose rates which may be encountered in space present potential health risks to space workers. This section discusses the biological and health effects of the different radiations encountered in the space environment and is based upon data currently available from human epidemiological surveys, laboratory animal studies, and space experimentation. The effects on health are considered in two general categories: early or acute effects, and late or delayed effects. Early effects are those occurring within hours, days, or a few weeks following high-dose, whole-body exposure. Late or delayed effects usually occur months to years following exposure and include cancer-induction, developmental abnormalities in the newborn, genetically related ill-health, lens cataracts, shortened lifespan, and impairment of fertility. The special problems of HZE-particle induced health effects are also discussed.

\section{EARLY EFFECTS}

Early radiation health effects assume clinical significance only with whole-body dose equivalent greater than 150 rem received in relatively short time periods (minutes to hours). Such exposure levels are likely to be encountered only during major solar particle events or during nuclear detonations in space.

Radiation is similar to other potentially hazardous physical or chemical agents in that high doses can produce tissue and organ injury, illness, and possibly death. The principle site of biological action of ionizing radiation is the proliferating cells of the renewal system of the organism, such as the bone marrow and intestinal epithelium and spermatogonia. Within these cell renewal populations, the most sensitive cell is the progenitor or stem cell. When the supply of functional cells is temporarily disrupted, the result is impaired function of that tissue or organ and potentially serious injury to the individual. If the therapeutic measures are inadequate or regeneration of the depleted cell population does not occur soon enough, the individila? may die. Damage to bone marrow and the intestine may cause death within 7 to 60 days after acute exposure to whole-body dose of radiation greater than a few hundred rad of low-LET radiation.

Cellular depletion in tissues and organs that contain large numbers ur dividing cells, e.g., in the bone marrow, lymphopoietic tissues, and testis, can be detected at doses as low as 50 rad delivered in short time periods, and are readily evident at doses of 100 to 150 rad. Death does not occur at these dose levels, although severe cellular depletion can be observed in some non-vital renewing organs, such as the testis. Whole-body radiation doses in the 200- to 400-rad 
range causes severe bone marrow depletion leading to symptoms related primarily to a decrease of circulating neutrophils and platelets in the blood. This results in the bone-marrow syndrome. The signs and symptoms are infection in a variety of body tissues due to neutropenia, severe bleeding in tissues and organs due to thrombocytopenia, and possibly death within 20 to 40 days after exposure. Effective treatment consists of neutrophil transfusions, protection of the individual against infection, and fresh platelet transfusions to control bleeding. Replacement of hematopoeitic stem cells by bone marrow transfusions from compatible donors may also provide effective therapy after exposure to doses where bone-marrow damage is a lethal threat, (Bond et. al., 1965; Mathe and Schwarzenberg, 1979).

\section{LATE EFFECTS}

Consideration here is given primarily to those delayed or late health effects in human beings following exposure to low-LET radiation, $x$-rays, and gamma rays from radioactive sources since these are the ionizing radiations most often encountered on Earth (e.g., in the nuclear industry and in medicine) and about which we have sufficient human data. Little consideration is given to high-LET neutrons and alpha particles. Briefly, low-level radiation can affect the cells and tissues of the body in three important ways. First, if the lesion occurs in one or a few cells, such as those of the hematopoietic tissues, the irradiated cell can occasionally transform into a cancer cell, and after a period of time, there is an increased risk of cancer developing in the exposed individual (carcinogenesis). Second, if the embryo or fetus is exposed during gestation, injury can occur to the proliferating and differentiating cells and tissues, leading to abnormal growth and development (teratogenesis). Third, if the lesion occurs in the reproductive cells of the testis or the ovary, the genome of the germ cell can be altered, and the injury can bc cxpressed in the descendants of the exposed individual as genetically-related $i 11$ health.

There are a number of other biological effects of ionizing radiation, such as cataracts of the lens of the eye, or impairment. of fertility, but the three important late effects--carcinogenes is, mutagenesis and teratogenesis--stand out as those of greatest concern. A considerable amount of information is available from epidemiological studies of exposed human populations and from laboratory animal experiments. Furthermore, we believe that exposure to ionizing radiations, even at very low levels of dose, carries some risk of such deleterious effects. As the dose of radiation increases above very low levels, the risk of these deleterious health effects increases in exposed human populations. Because some risk is present at any level of exposure, the exposure must be kept to a minimum commensurate with accomplishing the mission. 
A number of observations on the late health effects of low-level radiation have been made about which there is reasonably good general agreement. These observations are based primarily on careful evaluation of epidemiological surveys of exposed human populations, on extensive research in laboratory animals, on analysis of dose-response relationships of carcinogenic, teratogenic and genetic effects, and on known mechanisms of cell and tissue injury in vivo and in vitro (NAS-BEIR, 1972, 1977, 1980; UNSCEAR, 1977; NC $\overline{R P}, 1980)$.

1. Cancer is the most important late somatic effect of low-dose ionizing radiation. Different organs and tissues appear to vary greatly in their relative susceptiblity to cancer-induction by radiation. The most frequently occurring radiation-induced cancers in man include, in decreasing order of susceptibility: the female breast; the thyroid gland; the hematopoietic tissues; the lung; certain organs of the gastrointestinal tract; and bone. There are influences, however, of sex. age at the time of irradiation, and age at. the time of expression of the disease.

2. The effects of growth and development in the irradiated embryo and fetus are related to the gestational stage at which exposure occurs. It appears that a threshold level of radiation dose and dose rate may exist. below which gross teratogenic effects will not be observed. However, these dose levels would vary greatly depending on the particular developmental abnormality and on the radiation types and qualities.

3. Estimations of the radiation risks of genetically-related illhealth are based essentially entirely on laboratory animal observations, primarily from laboratory mouse experiments, because of the lack of data on exposed human populations. Scientific knowledge of fundamental mechanisms of radiation injury at the genetic level is far more complete than, for example, of mechanisms of radiation carcinogenesis, thereby permitting greater assurance in extrapolating information on genetic mutagenes is from laboratory animal experiments to man. Mutagenic effects are related linearly to radiation dose even at very low levels of exposure at low dose rates.

In spite of a thorough understanding of these late health effects in exposed human populations, there is still considerable uncertainty about the potential delayed health effects of low-level radiation. These uncertainties are discussed in the sections that follow. 
CANCER

Cancer is the second leading cause of death in the general population in the United States. It is estimated that about 25 percent of the U.S. population will eventually develop cancer (not including nonmelonoma skin cancer) and that about $16: 5$ percent of the population will eventually die of cancer.

Cancer is expected to be the most important delayed somatic effect in workers exposed to radiation in the space environment. Radiation causes an increase in the cancer risk after whole-body exposure to low. LET radiation at dose equivalents greater than 50 to 100 rem. At lower levels, it is difficult or impossible to demonstrate an increased risk even from epidemiological surveys of large populations exposed to lowlevel radiation. Risk estimates of possible cancer-induction at lowdose levels must necessarily depend more on the dose-response models and on the projection models used in the risk coefficient calculations than on the epidemiological data themselves. The risk of cancer from low-dose, low-LET whole body radiation is a problem of detection of statistically increased incidence of the disease over the normal expectation in the population in the absence of any additional radiation exposure.

Radiation-induced cancer may, as at least an initial step, involve random changes in DNA. Hence, late effects occur only on a chance basis in the relatively rare individual (i.e., almost all survivors of high-dose exposure will live out their normal life span). For example, in the 1974 ABCC study in Hiroshima and Nagasaki of the 70,000 deaths from all causes among 285,000 Japanese atomic bomb survivors exposed at all dose levels, it is estimated that approximately 400 to 500 persons, or 0.7 percent, nad died from radiation-induced cancer (Finch, 1979).

Cancers induced by radiation are indistinguishable from the ir normally-occurring counterparts; cause and effect cannot be established with certainty on an individual basis. This, together with the low overall induced cancer incidence rate even at high doses, make it difficult or impossible to detect directly or define the carcinogenic effects of low dose equivalents of radiation (in the range of a few rem or less).

Although the cancer risk may be increased at the time of irradiation, a cancer induced does not begin to appear until after a minimal latent period has passed. The duration (or plateau) of the apparent radiation-induced increase in incidence of solid cancers (i.e., cancers other than leukemia), which tend to have long latent periods, are not 
yet completely known. On the other hand, the duration of apparent radiation-induced increase in incidence of leukemia, which has a relatively short modal latency, is better known.

1

Uncertainties in Dose-Response Relationships for Radiation-Induced Cancer

A general hypothesis for estimation of excess cancer risk in irradiated human populations, based on theoretical considerations, on extensive laboratory animal studies, and on limited epidemiological surveys of exposed human populations, suggests various and complex doseresponse relationships between radiation dose and observed cancer incidence (NAS-BEIR, 1980). Models, with increasing complexity, include the linear, the pure quadratic, the quadratic (with a linear term), and finally, the multicomponent quadratic form with a linear term and with an exponential modifier (Figure B-1). One of the most widely considered models for cancer-induction by radiation, based on the available information and consistent with both knowledge and theory, takes the complex quadratic form: $I(D)=\left(\alpha_{0}+\alpha_{1} D+\alpha_{2} D^{2}\right) \exp \left(-\beta_{1} D-\beta_{2} D^{2}\right)$, where $I$ is the cancer incidence in the irradiated population at radiation dose $D$ in rad, and $\alpha_{0}, \alpha_{1}, \alpha_{2}, \beta_{1}$ and $\beta_{2}$ are coefficients (Figure $B-1)$. This multicomponent dose-response curve contains (1) initial upward-curving linear and quadratic functions of dose, which represent the process of cancer-induction by radiation; and (2) a modifying exponential function of dose, which represents the competing effect of cell-killing at high doses. $\alpha_{0}$ is the ordinate intercept at zero dose, and defines the natural incidence of cancer in the population. $\alpha_{1}$ is the initial slope of the curve at zero dose, and defines the linear component in the low-dose range. $\alpha_{2}$ determines the upward-curving quadratic function of dose. $\beta_{1}$ and $\beta_{2}$ determine the slope and curvature of the downward-curving function in the high-dose range, and define the cell-killing function. In the case of epidemiological surveys, this complex general dose-response form cannot be. universally applied. Therefore, the model is simplified by eliminating the parameters which have the least effect on the form of the doseresponse relationship in the dose range of low-level radiation.

The present SPS Committee believes:

1. Some experimental and human data, as well as theoretical considerations, suggest that for exposure to low-LET radiation, such as $x$-rays and gamma rays, at low doses, the linear model probably leads to overestimates of the risk of most radiation-induced cancers in man. Generally, data from high dose exposures in man and animals are used for estimating risk coefficients for the various models. To the extent that a quadratic term plays a role in actual response, high dose data extrapolated linearly to zero will tend to overestimate $\alpha$, the linear term. The use of data in this fashion can certainly be used to define the upper limits of risk. 
SHAPES OF DOSE RESPONSE CURVES
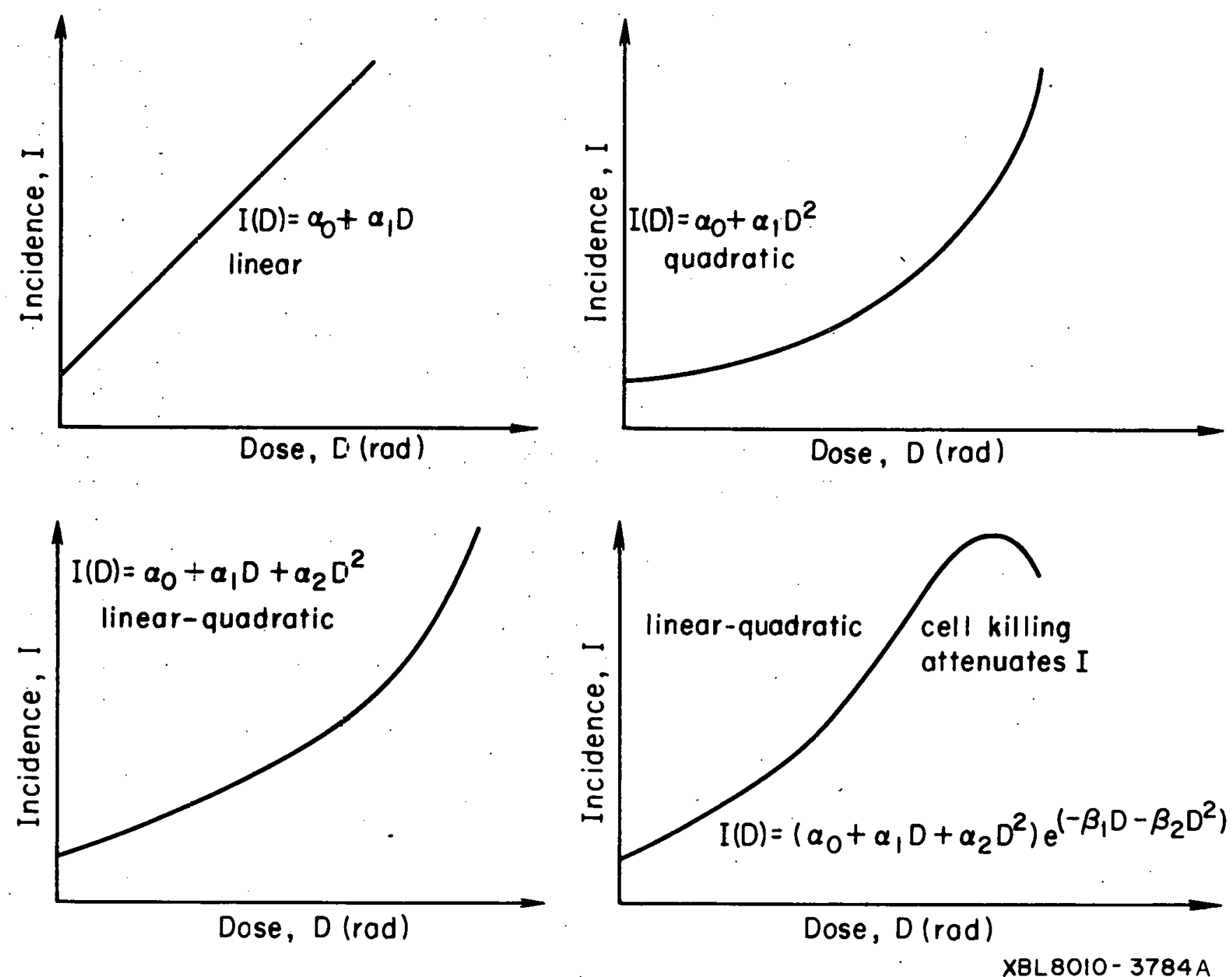

Figure B-1. Shapes of dose response curves (NAS-BEIR, 1980). 
2. The pure quadratic model may be used.to define the lower limits of risk from low-dose low-LET radiation.

3. For exposure to high-LET radiation, such as neutrons and heavy charged particles, the linear model is considered to be the most appropriate (NAS-BEIR, 1980).

4. For low dose and/or dose-rate exposure where reliable human data do not exist, the evidence from laboratory animal data indicates that a more accurate excess cancer risk may be smaller by a factor of perhaps two or more than that estimated using the linear model (NRC, 1975; UNSCEAR, 1972 and 1977; NCRP, 1975 and 1980): This reduction, however, would probably apply only to the low-LET fraction of the total dose.

Estimation of Space Radiation Induced Carcinogenic Risk in Man

Additional poorly understood factors affect the quantitative estimation of carcinogenesis at low-dose radiation. These include: the length of the latent period; the RBE for high-LET radiations, particularly for fast neutron and heavy charged-particle radiation relative to gamma and $x$-radiation; the special health effects of HZE particles; the period during which the radiation risk is expressed; the model used in projecting risk beyond the period of observation; the effect of dose rate or dose fractionation; and the influence of differences in the natural incidence of specific types of cancer. In addition, uncertainties are introduced by the biological risk characteristics of humans, for example, the effect of age at irradiation, the influence of any disease for which radiation was given therapeutically, and the influence of length of observation or follow-up of the study populations. The collective influence of these uncertainties limits the precision with which estimates of human cancer risk can be made for radiation exposure in the space environment.

The BEIR-III Report (NAS-BEIR, 1980) is used here as the source for cancer risk estimation. The chief sources of epidemiological data used in that report are the Japanese populations exposed to whole-body irradiation in Hiroshima and Nagasaki, the patients with ankylosing spondylitis and other patients who were exposed to partial body irradiation therapeutically or to diagnostic medical $x$-rays and the varlous occupationally-exposed populations, such as uranium miners and radium dial painters. Most epidemiological data do not systematically cover the range of low to moderate radiation doses for which the Japanese atuinic bomb suryivor data apjedr to be fairly reliable (NASRERF, 1977; UNSCEAR, 1977). Analysis in terms of dose-response, therefore, necessarily rely greatly on the Japanese data. The substantial neutron component of dose in Hiroshima makes this data of great value in estimating cancer risk for high-LET radiation. The Nagasaki data, for which the neutron component of dose is small, are not reliable for 
doses below 100 rad, but can be useful for estimating cancer risk from higher doses of low-LET radiation. The recent calculations of the BEIR III Report (NAS-BEIR, 1980) provides the most current bas is for estimating the carcinogenic risk from radiation in SPS workers in the space environment. This report (NAS-BEIR, 1980) chose three exposure situations for illustrative computations of lifetime cancer risk of low-dose, low-LET, whole-body radiation:

1. A single exposure of a representative (life-table) population to $10 \mathrm{rad}$;

2. A continuous, lifetime exposure of a representative (lifetable) population to 1 rad per year;

3. An exposure to 1 rad per year over several age intervals exemplifying conditions of occupational exposure.

These three exposure situations reflect circumstances that might normally occur--i.e., the general and worker populations and single and continuous exposure.

The selected level of chronic exposure of one rad per year, although only one-fifth the maximal permissible dose for conventional occupational exposure is nevertheless consistent with the occupational exposure experience in the nuclear industry. The United States'19691971 life-table was used as the basis for the calculations (NAS-BEIR, 1980). The expression time was taken as 25 years for leukemia and the remaining years of life for other cancers. Two projection.models were used, the absolute risk and the relative risk models. The absolute $r i s k$ is the expression of excess cancer risk due to radiation exposure as the arithmetic difference between the risk among those in the exposed population and that obtaining in the population in the absence of radiation exposure. The relative risk is the expression of excess cancer risk due to radiation exposure as the arithmetic ratio of the risk among those in the exposed population to that obtaining in the population in the absence of radiation exposure.

In the absence of any increased radiation exposure, among one million persons of life-table age and sex composition in the United States, about 164,000 persons would normally be expected to die from cancer, according to present cancer mortality rates. For a situation in which these one million persons are exposed to a single dose increment of 10 rad of low-LET radiation, the linear-quadratic dose-response model (LQ-L)* predicts increases of about 0.5 percent to 1.4 percent (about 750-2,300 cancer cases) over the normal expectation of cancer

\footnotetext{
* Linear-Quadratic (LQ) for low-LET radiation, linear (L) for high-LET radiation.
} 
mortality, according to the projection model used. The linear model $(L-L)^{\star \star}$ predicts increases of about 1 percent to 3 percent (about $1,700-5,000$ cancer cases) over the normal expectation, depending on the projection model. The pure quadratic model. (Q-L) ${ }^{\star \star \star}$ predicts increases of about 0.06 to 0.2 percent (about 100-300 cancer cases) over the normal expectation of cancer mortality, according to the projection model used. The calculations are summarized in Table B-1 taken from the BEIR III Report (NAS-BEIR, 1980). The upper and lower limits of these cancer mortality-risk estimates suggest a wide range. of values which may differ by as much as an order of magnitude. The uncertainty derives mainly from the dose-response models used, from the alternative absolute and relative projection models, and from the sampling variation in the source data. The lowest risk estimates--the lower bound of the range--are obtained from the pure quadratic model; the highest--the upper bound of the range--from the linear model; and the linear-quadratic model provides estimates intermediate between these two extremes.

For continuous lifetime exposure to one rad per year, the increase in cancer mortality, according to the linear-quadratic dose-response model ( $L Q-L$ ), ranges from about three percent to eight percent (about $5,000-13,000$ cancer cases) over the normal expectation, depending on the projection model. The linear model ( $L-L)$ predicts increases of about 7 percent to 18 percent (about 11,000 to 30,000 cancer cases) over the normal expectation. The quadratic dose-response model (Q-L) cannot be applied to this calculation. The calculations are summarized in the BEIR III Report (NAS-BEIR, 1980).

The calculations for continuous exposure to one rad per year from the BEIR III Report (NAS-BEIR, 1980) segments the population into several age intervals, viz. 20-65 years, 35-65 years, and 50-65 years, exemplifying conditions of occupational exposure over a working career. For the increasing age groups, much of the variation in cancer risk estimates is due to the total dose received for the different periods of continuous exposure. The excess cancer mortality decreases with increasing age interval due almost completely to the total dose received rather than on the projection model used. For exposure at 35-65 years and 50-65 years, the two projection models give nearly identical results.

\footnotetext{
$* *$ Linear (L) for low-LET radiation, linear (L) for high-LET radiation.

${ }^{* * *}$ Quadratic (Q) for low-LET radiation, linear (L) for high-LET radiation.
} 
Table B-1 Estimated excess mortality per million persons from all forms of cancer, single exposure to 10 rads of low-LET radiation, by dose-response model.*

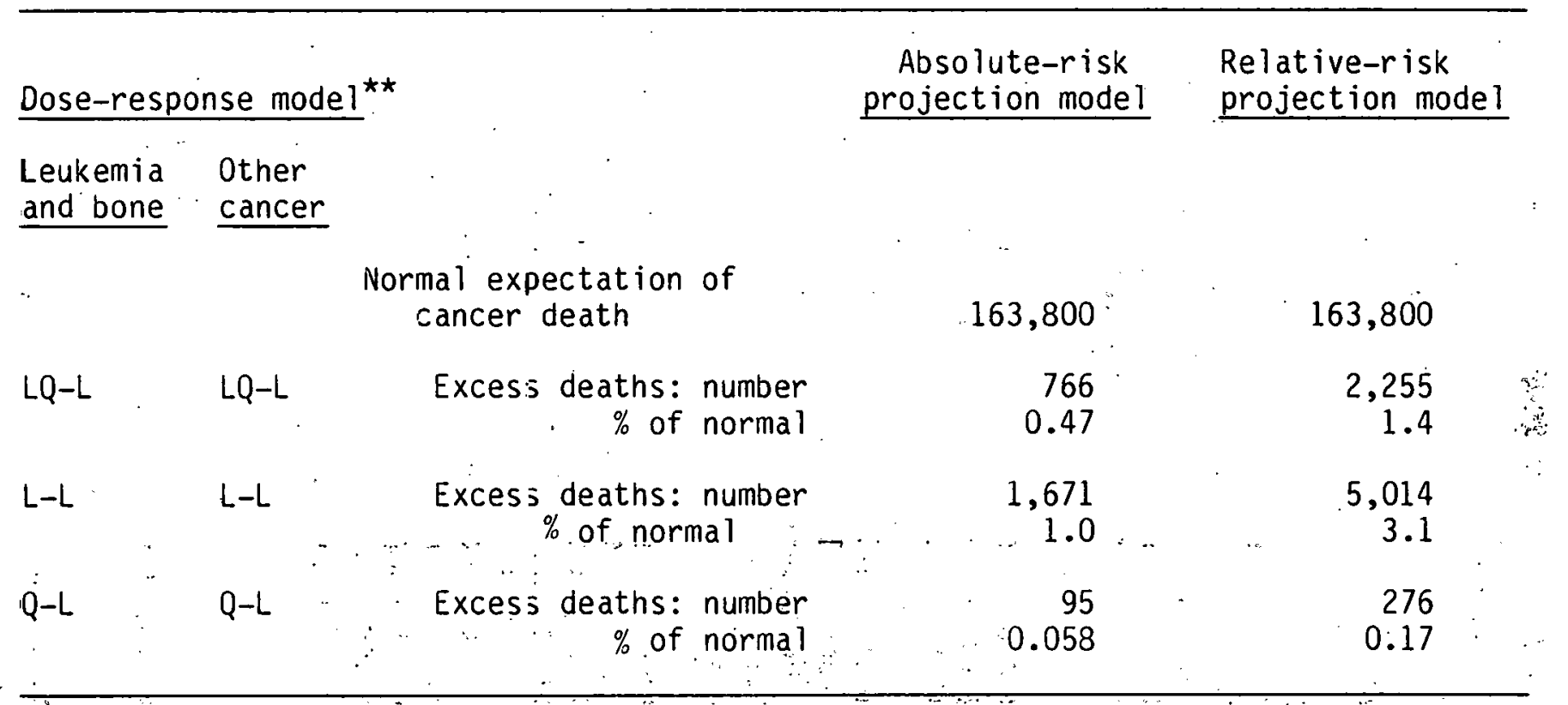

* NAS-BEIR (1980)

${ }^{\star \star}$ See text. 


\section{GENETICALLY RELATED ILL-HEALTH}

At low-level radiation exposure the effects of radiation include genetic disorders which depend on changes in individual genes (gene mutations) and in chromosomes (either in total number or in gene arrangement, or chromosomal aberrations): Low-level ionizing radiation causes genetic disorders (genetic mutations) in laboratory animals, and it is assumed that the same applies in man. The se effects may be manifested in man as genetically related ill-health (e.g., mental retardation in descendants of irradiated parents). Gene mutations are expected to have greater health consequences than changes in chromosomes. The genetic effects arising from either are proportional to dose. In estimating genetic disorders caused by gene mutations, the BEIR III Report (NAS-BEIR, 1980) considered two exposure situations: continuous exposure over the lifetime of an individual. and single exposure of the parents only.

It is estimated that since genetic effects produced are proportional to radiation dose, only about one percent to six percent of all spontaneous mutations in humans are due to natural background radiation. The incidence of numan genetic disorders in the absence of any additional radiation exposure is about 107,000 cases per million (about 10.7 percent) liveborn offspring (NAS-BEIR, 1980). A smal.). increase in radiation exposure above background will lead only to a correspondingly small relative increase in the mutation rate. The doubling dose equivalent, i.e., the radiation dose equivalent required to produce as many more mutations as are already occurring spontaneously, is estimated to be 50 to 250 rem. The lower the doubling dose equivalent, the greater is the genetic risk from a given exposure... It is estimated that at equilibrium the increase in human genetic disorders in the population could be about 60 to 1,100 per, million liveborn offspring per rem of parental exposure received each generation. before conception.

An averaqe parental exposure of one rem before conception is expected to produce 5 to 65 additional genetic disorders per million live-born offspring in the first generation. These estimates are taken from the BEIR III Report (NAS-BEIR, 1980). Since the risk is conservatively taken to be linear at the dose levels of concern, the risk can be scaled readily for any dose equivalent.

\section{DEVELOPMENTAL ABNORMALITIES IN THE NEWBORN}

Among the somatic effects of low-level ionizing radiation other than cancer-induction, developmental abnormalities in the newborn are of greatest concern (NAS-BEIR, 1980). Exposure to high doses (hundreds of rads) of the embryo or fetus during gestation causes death, developmental abnormalities, retardation of growth, and functional impairment. There appears to be a threshold level for the induction of gross malformations in the newborn depending on the developmental stage 
during gestation at which the exposure occurred and for the particular abnormality considered. Threshold doses for some abnormalities have been demonstrated, but such thresholds vary for different abnormalities. Recent data from the Japanese atomic bomb studies demonstrate measurable teratogenic damage (e.g., small head size associated with mental retardation) at doses of 10-19 rad (kerma) (NAS-BEIR, 1980). Decreasing the dose rate generally leads to a decrease in the developmental effects.

\section{EFFECTS ON THE EYE}

Cataracts. The most important response of the human eye to chronic radiation exposures is the production of cataracts resulting in impairment or loss of vision. The committee believes that cataract induction in space workers may be a problem, depending in part on the fluence and the RBE of the HZE particles. Impairment of vision in man can occur after single and fractionated exposure to low- and high-LET radiations (Britten et al., 1966). The response, including the length of the latent period and the severity of the effect, is dose-dependent above a threshold level. The dose-response curve for low-LET radiation-induced cataracts is highly sigmoid (Merriam and Focht, 1962). Above the threshold, the incidence of lens changes increases non-linearly with dose, the time to appearance is shortened, and the number of opacities that progress to cataracts with visual impairment inereases. Opacities occur with doses from 200 to $500 \mathrm{rad}$, but do not progress to cataracts. Opacities may occur with 400 rad when the dose is fractionated over a period of three weeks and with $600 \mathrm{rad}$ if the fractionation extends beyond three months. For low-LET radiations, protraction of the exposure is thought to reduce the effect on the lens less than for some other tissues.

Workers exposed to fast neutrons from cyclotrons have developed cataracts (Abelson and Kruger, 1949); however, precise dose levels are not known, and a reliable quality factor cannot be derived. In radiotherapy patients exposed to 14-MeV cyclotron neutrons, no change in the lens was seen following 80 rad in 12 fractions. However, slight permanent vision loss was found after 220 rad (Roth et al., 1976). Despite a knowledge of the neutron dose in the Japanese atomic bomb survivors, the neutron dose effect on the induction of cataracts is not known. Therefore, the RBE for cataract induction in man remains unknown, although the RBE will be dependent on the dose.

Although rodents are considered much more susceptible than humans to radiation-induced cataracts, rodent studies provide data on LET-RBE relationships that may obtain for human risk estimation. The mouse lens is sensitive to high-LET neutrons; the RBE at doses less than 10 rad could approach 100 or greater when "fleck" opacities are scored. The human lens would also be expected to be sensitive to densely ionizing radiations, such as neutrons or HZE particles (Merriam et al., 
1965; Batemann and Snead, 1969). Current research with rabbits exposed to single doses of various heavy charged particles or photons should provide additional. information for risk estimation (Lett et al., 1980).

\section{FERTILITY}

\section{Female.}

Sensitivity to radiation-induced sterility varies with age (NAS$B E I R, 1980$ ); women under 40 years require larger doses to induce menopause than women over 40 years. Doses below 100 rad are likely to have no effect on fertility or may produce transient sterility for a few months. Doses on the order of 170 rad can result in temporary sterility for from one to several years. However, a small percentage of women may be permanently sterilized by doses as low as $125 \mathrm{rad}$. Doses of 200 to 650 rad are required to sterilize five percent of women for more than five years. Doses of 625 to 2000 rad or more are required to sterilize 50 percent of women (Lushbaugh and Casarett, 1976). Protraction or fractionation of dose reduces the injury to the ovary (UNSCEAR, 1962). Fractionated doses greater than 2000 rad does not always produce sterility (Baker, 1971).

Male.

The seminiferous epithelium is among the most radiosensitive tissues in the adult. An acute dose of 15 rad will cause a significant decrease of the sperm count in about 40 percent of normal men within approximately two months (Langham, 1967; Paulson, 1973). A dose of 30 to 50 rad results in aspermia and temporary sterility or infertility from a low sperm count. At this dose level, all sperm counts will return to normal after 9 to 19 months (Paulson, 1973). Doses up to $400 \mathrm{rad}$ cause temporary sterility and/or infertility lasting up to 30 months (Paulson, 1973; Rowley et al., 1974). With testis exposures up to $600 \mathrm{rad}$, sterility followed by infertility may last for a period of five years or more (Rowley et al., 1974); but recovery may occur without serious physiological alterations.

Human data suggest that long periods of exposure to low dose rates can cause infertility. Men receiving radiotherapy for. Hodgkin's disease and unavoldably receiving a daily dose of 10 to 15 rad to the testes (total of 140 to $300 \mathrm{rad}$ ) became sterile with no evidence of recovery for up to 40 months (Speiser et a1., 1973). In occupationally exposed Roumanian workers, there was about 35 to 75 percent incidence of infertility (Popescu and Lancranjan, 1975) for periods of occupational exposure ranging from 2 to 22 years at 0.5 to 9.3 rad per year (0.01 to 0.2 rad per week). Thus, infertility could result with 90-day mission dose equivalents of 40 rem repeated over several years duration. 
Laboratory animal experiments (Lushbaugh and Casarett, 1976; Langham, 1967), and limited human data on effects of protracted or fractionated low-dose exposures on spermatogenesis, indicate that fractionation of dose at low levels may be more effective on spermatogenesis than acute exposure because of the cyclic process of spermatogenesis (Lushbaugh and Casarett, 1976; Kramer et al., 1974).

\section{OTHER HEALTH EFFECTS OF RADIATION}

As stated above, carcinogenesis, mutagenesis, and cataractogenesis are the health effects of principal concern. At low doses of radiation, cancer induction or promotion probably accounts for all excess mortality in experimental animals and man (NAS-BEIR, 1980). However, low doses of radiation may accelerate the appearance time of some nonlethal conditons (e.g., vascular or renal diseases) and thereby contribute to late life morbidity. The impact of such morbidity from non-neoplastic diseases is thought to be small, in comparison with neoplasia, based on life-span studies on mice (Storer et al., 1979; Sacher, 1976).

Vascular disease occurs as a consequence of aging in man and experimental animals. The vasculature of the mouse heart appears quite sensitive to high-LET neutron radiation, even at low doses (20 rad), and the expression of vascular disease occurs earlier than in aged controls (Yang et a1., 1978; Stearner et al., 1979). Also, the degree of vascular injury is increased, in comparison with the same single dose, by fractionation of fission neutron doses over several months. Vascular sensitivity of man to HZE particles is unknown, but neither vascular injury nor other adverse health effects are considered to be of significance for space workers.

\section{HZE Particle Radiation Effects}

The potential health hazard of HZE particles (stripped atomic nuclei with $Z>2$ ) from galactic space was suggested soon after their discuvery. Tobias (1952) predicted that a single HZE particle could cause light sensation in the retina and suggested that a single HZE particle might kill or modify a column of living cells in tissues. Neon and argon particles at energies of about $0.5 \mathrm{GeV} /$ nucleon have been shown by several authors (Worgle, 1980; Malachowski, 1978; A. Nelson, 1980) to produce lesions in various eye structures of the rodent which appear to be track related phenomena as predicted by Tobias. Some workers have unsuccessfully tried to relate neuronal killing in the CNS to such track related events.

The significance of this track and track structure related phenomenology to human hazard remains to be evaluated. It appears 
possible, at least, that HZE particles can indeed act in ways that are qualitatively different from the more classical interaction models associated with other radiations. For purposes of this report, dose from HZE particles is ignored, considering all the other uncertainties in dose estimation. 


\section{APPENDIX C}

\section{GLOSSARY}

Aspermia: The absence of sperm or a marked decrease in sperm count.

Bremsstrahlung: Secondary photon radiation produced by deceleration of charged particles.

Cataractogenesis: The induction of cataracts in the lens of the eye.

Dose:

A general form denoting the quantity of radiation or energy absorbed. For special purposes, it must be appropriately qualified. If, unqualified, it refers to absorbed dose.

Absorbed dose: The energy imparted to matter by ionizing radiation per unit mass of irradiated material at the place of interest. The unit of absorbed dose is the rad.

Accumulated dose: Total dose resulting from repeated exposure to radiation.

Dose equivalent (DE): Quantity that expresses all. radiations on a common scale for calculating the effective absorbed dose. It is defined as the product of the absorbed dose in rad and certain modifying factors (See Quality Factor). The unit of $D E$ is the rem. For example, the radiation risk from one rem of any ionizing radiation is assumed to be equivalent to that from one rad of low-LET radiation.

Dose rate: Absorbed dose delivered per unit of time.

Electron: A subatomic particle with a negative electrical charge.

Electron flux density:

Electrons per square centimeter per second.

Electron volt: A unit of energy equivalent to the energy gained by an electron in passing through a potential difference of one volt. Larger multiple units of the electron volt are frequently used: KeV for thousand or kilo electron volts; MeV for million or mega.

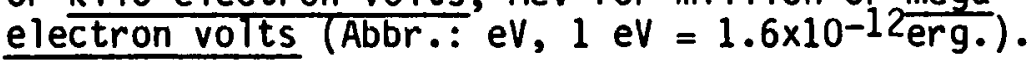


Exposure:

A measure of the ionization produced in air by $X$ or gamma radiation. It is the sum of the electrical charges on all ions of one sign produced in air when all electrons liberated by photons in a volume element of air are completely stopped in air, divided by the mass of the air in the volume e lement.

The special unit of exposure is the roentgen.

Fluence:

Particles per square centimeter.

Galactic cosmic rays (GCR):

High-energy nuclei with origins outside our solar system, probably originating in supernova explosions of stars or in the remnants of these explosions.

Geosynchronous

orbit (GEO):

(or Geostationary orbit). An orbit at an altitude of approximately $36,000 \mathrm{kilometers.}$

Homeostasis:

The steady state for equilibrium in the living body with respect to various functions and to the chemical compositions of the fluids and tissues; the processes through which such body equilibrium is maintained.

High-energy, heavy ions ( $H Z E$ )

High energy heavy particles having a nuclear charge (Z) in excess of 2 .

Incidence: $\quad$ The rate of occurrence of a disease within a specified period of time; usually expressed in a number of cases per million $\left(10^{6}\right)$ per year.

Ion:

Atomic particle, atom, or chemical radical bearing an electrical charge, either negative or positive.

Ionization: The process by which a neutral atom or molecule acquires a positive or negative charge.

Primary ionization: In collision theory, the ionization produced by the primary particles as contrasted lo lhe "total ionization" which includes the "secondary ionization" produced by delta rays. Secondary ionization: Ionization produced by delta rays.

Ionization

density: Number of ion pairs per unit volume. 
Ionization

path (track): The trail of ion pairs produced by an ionizing radiation in its passage through matter.

Ionizing radiation:

Any electromagnetic or particulate radiation capable of producing ions, directly or indirectly, in its passage through matter.

Secondary radiation: Radition resulting from absorption or other radiation in matter. It may be either electromagnetic or particulate.

Kerma:

The quotient of $d E_{t r}$ by $d m$, where $d E_{t r}$ is the sum of the initial kinetic energies of all the charged particles liberated by indirectly ionizing particles in a volume element of the specified material, and $\mathrm{dm}$ is the mass of the matter in that volume element.

$$
K=\frac{d E_{t r}}{d m}
$$

Kerma has the same dimension as absorbed dose and both quantities have the same special unit, the rad. The unit in the International System of Units

(SI) is the gray, symbol Gy; 1 Gy $=1 \mathrm{~J} \mathrm{~kg}^{-1}=100 \mathrm{rad}$.

Latent period: The period or state of apparent non-effectiveness between the time of exposure of tissue to an injurious agent and response to that exposure.

Linear energy

transfer (LET): The average amount of energy lost per unit of particle track length.

LOW-LET: Radiation energy transfer characteristic of electrons, $x$-rays, and Gailina rays.

High-LET: Radiation energy transfer characteristic of heavy charged particles or fast neutrons.

Linear no threshhold hypothesis: The assumption that a dose-effect curve derived from data in the high dose and dose-rate ranges may be extrapolated linearly through the low dose and low dose range to zero, implying that, theoretically, any amount of radiation may cause some damage.

Low earth orbit (LEO):

Orbit at an altitude of approximately $500 \mathrm{~km}$. 
Mutagenesis:

Neoplasm:

Photon:

Quality

factor $(Q)$ :

Rad:

Radiosensitivity:

Relative Bio-

logical

Effectiveness

(RBE):
Alterations in the genes that result in a mutation.

Any new abnormal growth. The term "neoplastic disease" refers to the occurrence of either malignant or benign tumors.

In the quantum theory of light, light consists of tiny bundles of energy. Each bundle is a photion.

The 1 inear-energy-transfer-dependent factor by which absorbed doses are multiplied to obtain (for radiation protection purposes) a quantity that expresses-on a common scale for all ionizing radiations--the effectiveness of the absorbed dose.

The standard unit of absorbed dose, equal to energy absorption of 100 ergs per gram or 0.01 Joules per kilogram; supercedes the roentgen as the unit of dosage. One mrad is 0.001 rad. ICRU currently recommends use of the gray (Gy) as the measure of absorbed dose; $1 \mathrm{~Gy}$ is equal to $100 \mathrm{rad}$.

Relative susceptability of cells, tissues, organs, organisms of any living substance to the injurious action of radiation. Radiosensitivity and its antonym radioresistance are currently used in a comparative rather than an absolute sense.

The RBE is a factor used to compare the biological effectiveness of absorbed radiation doses (i.e., rads) due to different types of ionizing radiation; more specifically, it is the experimentally determined ratio of an absorbed dose of a radiation in question to the absorbed dose of a reference radiation required to produce an identical biological effect in a particular experimental organism or tissues. The RBE is the ratio of rem to rad. (If 1 rad of fast neutrons equalled in lethality 3.2 rads of KVP $x$-rays, the RBE of the fast neutrons would be 3.2 ).

Rem:

A special unit of dose equivalent. The dose equivalent in rem is numerically equal to the absorbed dose in rad multiplied by the quality factor, $Q$, and any other necessary modifying factors. The rem represents that quantity of radiation that is equvalent--in biological damage of a specified sort--to 1 rad of 250 KVP $x$-rays. 
ICRU currently recommends use of the sievert (Sv) as the measure of dose equivalent; $1 \mathrm{~Sv}$ is equal to 100 rem.

Solar cell: $\therefore$.

A photovoltaic cell that converts light energy into electrical energy.

Solar radiation: The total electromagnetic radiation emitted by the sun.

Solar particle

event (SPE): An event caused by large magnetic upheavals on the solar surface which accelerate protons--and to a lesser extent, heavier nuclei--to high energies and projects these particles into space.

South Atlantic Anomaly:

A region of the trapped particle zones which dips close to Earth in the southern Atlantic ocean southeast of the Brazilian coast. This area is the most important source of radiation for space workers in LEO.

SPS:

Satellite power systems.

Transfer

ellipse (TE): The path followed by a space vehicle in moving from one point in space to another (for example, from LEO to GEO). 


\section{REFERENCES}

P. H. Abelson and P. G. Kruger, "Cyclotron-Induced Radiation Cataracts," Science, 110, 655-657 (1949).

H. R. Anderson, "The Radial Gradient of Cosmic Radiation Measured by Mariners 2 and 4," J. Geophys. Res., 73, 2897-2909 (1968).

T. G. Baker, "Comparative Aspects of the Effects of Radiation during Oogenesis," Mutation Res., 11, 9-22 (1971).

J. L. Bateman, and M. L. Snead, "Current Research in Neutron RBE on Mouse Lens Opacity," in Proceedings of Symposium on Neutrons in Radiobiology Conference, November 5, 1969, pp. $192 \ldots 206$ (1969).

V. P. Bond, T. M. Theodor, and J. 0. Archambeau, Mammalian Radiation Lethargy, A Disturbance in Cellular: Kinetics, Academtc Press, New York (1975).

M.J.A. Britten, K. E. Halnan; and W. J. Meredith, "Radiation Cataract-New Evidence on Radiation Dosage to the Lens," Brit. J. Radiol:, 39, 612-617 (1966).

H. J. Crawford, P. B. Price, B. G. Cartwright, and J. D. Sullivan, "Solar Flare Particles: Energy-Dependent Composition and Relationship to Solar Composition," Astrophys. J., 195, No. 1, 213-221 (1 Jan. 1975).

S. B. Curtis, "Radiation Physics and Evaluation of Current Hazards," in Space Radiation Biology and Related Topics, C. A. Tobias and P. Todd, Eds., Academic Press, New York (1974) pp. 21-99.

S. B. Curtis, "Frequencies of Heavy lons in Space and Their Biologically Important Characteristics," Life Sci. Space Res., 209-214 (1973).

S. B. Curtis and M. C. Wilkinson, Study of Radiation Hazards to Man on Extended Missions, U. S. National Aeronautics and Space Administration Report NASA CR-1037 (1968).

S. Finch, "The Study of Atom Bomb Survivors in Japan," Am. J. Medicine, 66, 899-901 (1979).

Hardy, Personál Communication (1979). 
International Commission on Radiological Protection. Recommendations of the International Commission on Radiological Protection. ICRP Publication 26. Pergamon Press, 0xford (1977).

J. F. Janni and F. E. Holly (Eds.), The Current Experimental Approach to the Radiological Problems of Spaceflight, Aerospace Medicine (1969).

M. F. Kramer, J.A.G. Davies, and Th. P. A. van der Ven, "Effect of 1 MeV Fast-Neutrons on Spermatogonial Proliferation in Mice; Influence of Dose Fractionation with Different Intervals;" Int. J. Radiat. Biol., 24, 253-260 (1974).

W. H. Langham (Ed.), Radiobiological Factors in Manned Space Flight, NAS-NRC Publication 1487 (1967).

J. T. Lett, A. B. Cox, P. C. Keng, A. C. Lee, C. M. Su, and D. S. Bergtold, "Late Degeneration in Rabbit Tissues after Irradiation by Heavy Ions," in Life Sciences and Space Research, XVIII, R. Holmquist, ed., Pergamon Press (in press, 1980).

Y. I. Logachev, I. A. Savenko, and A. I. Sladkova, "Radiation Levels in Interplanetary Space from Data of the Prognoz Satellites," Cosmic Radiation, 12, No. 5, 716-718 (1974).

C. C. Lushbaugh and G. W. Casarett, "Effects of Gonodal Irradiation in Clinical Radiation Therapy, A Review," Cancer, 37, No. 2, 1111-1120 (1976).

M. J. Malachowski, The Effects of Ionizing Radiation on the Light Sensing Elements of the Retina, Ph.D. Thesis, University of California, Berketey (1978).

G. Mathe and L. Schwarzenberg, "Bone Marrow Transplant (19581978)," in Conditioning and Graft-versus-Host Disease, Indications in Aplasias and Leukemias Pathalogic and Biologic, Vol. 27, pp. 337-343 (1979).

G. R. Merriam, Jr., and E. F. Focht, "A Clinical and Experimental Study of the Effect of Single and Divided Doses of Radiation on Cataract Production," Trans. Amer. Opthalmol. Soc., 60, 35-51 (1962).

G. R. Merriam, B. J. Viavata, J. L. Bateman, H. H Rossi, V. P. Bond, Goodman, and E. F. Focht, "The Dependence of RBE on the Energy of Fast Neutrons, IV. Induction of Lens Opacities in Mice," Rad. Res. $25,123-138$ (1965).

National Council on Radiation Protection and Measurements, Influence of Dose and Its Distribution in Time on Dose-Effect Relationships for LOW-LET Radiation, NCRP Report No. 64 (1980). 
National Council on Radiation Protection and Measurements, Review of the Current State of Radiation Protection Philosophy, NCRP Report No. $43(1975)$.

National Academy of Sciences, G. W. Beebe, H. Kato and C. E. Land, "Mortality Experience of Atomic Bomb Survivors 1950-1974, Life Span Study Report 8, Radiation Effects Research Foundation Technical Report RERF TR 1-77 (1977) [Referred to as NAS-RERF].

National Academy of Sciences, D. Grahn, ed., HZE Particle Effects in Manned Spaceflight, Washington, D.C. (1973).

National Academy of Sciences, Radiological Effects of Ionizing Radiation, (the "BEIR Committee" Report, BEIR I), NAS/NRC (1972) [Keterred to as NAS-BEIR, 1977].

National Academy of Sciences, Radiological Effects of Ionizing Radiation, (The "BEIR Committee" Report, BEIR II), NAS/NRC (1977). [Referred to as NAS-BEIR, 1977].

National Academy of Sciences, Biological Effects of Ionizing Radiation, (The "BEIR Committee" Report, BEIR III), Revision of the 1972 Report (1980) [Referred to as NAS-BEIR, 1980].

A. Nelson, Theoretical and Observational Analys is of Individual Ionizing Particle Effects in Biological Tissues, Ph.D Thesis, University of California, Berkeley (1980).

Nuclear Regulatory Commission, "Calculations of Reactor Accident Consequences," Appendix VI of Reactor Safety Study (1975).

C. A. Paulsen, The Study, of Irradiation Effects on the Human Testes: Including Histologic, Chromosomal and Hormonal Aspects, Terminal Report, AEC Contract AT(45-1)-2225 (January 31, 1973).

11. Popescu and I. Lancranjan," "Spermatogenesis Alteration during Protracted Irradiation of Man," Health Physics, 28, 567-573 (1975).

M. L. Rossi and M. C. Stauber, "Radiation Protection Design Considerations for Man in Geosynchronous Orbits," IEEE Transactions on NuEl. Si. . NS-24, Nu. 6 (Decenber 1977).

J. B. Roth and M. Catteral, "Effects of Fast Neutrons on the Eye," Brit. J. Opthalmn 1., 60, 236-244 (1976).

M. J. Rowley, D. R. Leach, G. A. Warner, and C. G. Heller, "Effects of Graded Doses of Ionizing Radiation on the Human Testes, "Radiat. Res., 59, No. 3, 665-678 (September 1974). 
G. A. Sacher, "Dose, Dose Rate, Radiation Quality and Host Factors for Radiation-Induced Life-Shortening," in Aging, Carcinogenes is, and Radiation Biology, K. C. Smith, Ed., Plenum Press, New York (1976).

R. T. Santoro, R. G. Alsmiller, Jr., and K. C. Chandler, "Shielding of Manned Space Vehicles against Galactic Cosmic-Ray Alpha Particles," Trans. Amer. Nucl. Soc., 16, 335-336 (June 1973).

H. J. Schaefer, "Galactic Radiation Hazard in Long-Term Space Missions," Aerospace Medicine, 39, 271-276 (1968).

S. M. Seltzer, "Electron, Electron-Bremsstrahlung and Proton DepthDose Data for Space Shielding Applications, "in IEEE Trans. on Nucl. Sci., Vol. NS-26, No. 6, 4896-4904 (1979).

B. Speiser, P. Rubin, and G. Casarett, "Aspermia Following Lower Truncal Irradiation for. Hodgk.in's Disease," Cancer, 32, 692-698 (1973).

E. G. Stassinopoulos, "The Geostationary Radiation Environment," J. Spacecr. Rockets (1980).

E. G. Stassinopoulos, "A Preliminary Study of the Charged Particles Radiation for the Satellite Power System," in Workshop on the Radiation Environment of the Satellite Power System, Lawrence Berkeley Laboratory Report LBL-8581 (1979).

S. P. Stearner, V. V. Yang, and R. L. Devine, "Cardiac Injury in the Aged Mouse: Comparative Ultrastructural Effects of Fission Spectrum Neutrons and Rays;", Radiat. Res., 78, 429-447. (1979).

J. D. Storer, L. J. Serrano, E. B. Darden, J. R. McJerrigan, and R.:L. Urich, "Life-Shortening and K.F.M.' and Balb/c Mice as d Furicliuri of Radiation Quality, Dose, and Dose. Rate," Radiat. Res., 78, 122-161 (1979).

C. A. Tobias, "Radiation Hazards in High Altitude Aviation," J.:" Avia. Med. 23, 345-372 (1952).

United Nations Scientific Committee on the Effects of Atomic Radiation ("UNSCEAR"), Report for 1977 (1977).

United Nations Scientific Committee on the Effects of Atomic Radiation, UNSCEAR Report for 1972 (1972).

United Nations Scientific Committee on the Effects of Atomic Radiation, Supplement No. 16 (1.962).

U. S. Department of Energy and the National Aeronautics and Space Administration, Satellite Power System, Concept. Development and Evaluation Program, Reference System Report DOETER-0023 (October 1978). 
W. R. Webber, An Evaluation of the Radiation Hazard Due to SolarParticle Events, Boeing Co., Aero-Space Div., Seattle (Dec. 1963).

J. P. Wefe 1, "Instr.hentation for Radiation Measurement in Space," in Workshop on the Radiation Environment of the Satellite Power System (SPS), W. Schimmerling and S. B. Curtis (EdS.), U.S. Department of Energy Report CONF-7809164 (Dec. 1979).

J. W. Wilson, "Environmental Geophysics and SPS Shielding," in Workshop on the Radiation Environment of the Satellite Power system (SPS), W. Schimmerling and S. B. Curtis (Eds.), U.S. Department of Energy Report CONF-7809164 (Dec. 1979).

J. W. Wilson and F. M. Denn, Preliminary Analysis of the Implications of Natural Radiation on Geostationary Operations, NASA TND-8290 $(1976)$.

M. C. Wilkinson and S. B. Curtis, "Galactic Cosmic Ray Heavy Primary Secondary Doses," in Proceedings of the National Symposium on Natural and Manmade Radiation in Space, NASA TM X-2440, 104-107 (1972).

G. Worgle, Columbia University, Personal Communication (1979).

V. V. Yang, S. P. Stearner, and E. J. Ainsworth, "Late UItrastructural Changes in the Mouse Coronary Arteries and Aorta after Fission Neutrons or 60 Co Irradiation," Radiat. Res.; 74, 436-454 (1978). 
THIRD CLASS MAII

Official Business

Penalty for Private Use, $\$ 300$ 